\title{
Structure of the full kinetoplastids mitoribosome and insight on its large subunit maturation
}

\author{
Heddy Soufari ${ }^{1^{*}}$ \& Florent Waltz ${ }^{1^{*}}$, Camila Parrot ${ }^{1+}$, Stéphanie Durrieu ${ }^{1+}$, Anthony Bochler ${ }^{1}$, \\ Lauriane Kuhn ${ }^{2}$, Marie Sissler ${ }^{1}$, Yaser Hashem ${ }^{1 \neq}$

\begin{abstract}
${ }^{1}$ Institut Européen de Chimie et Biologie, U1212 Inserm, UMR5320 CNRS, Université de Bordeaux, 2 rue R. Escarpit, F-33600 Pessac, France

2 Plateforme protéomique Strasbourg Esplanade FRC1589 du CNRS, Université de Strasbourg, Strasbourg, France
\end{abstract}

${ }^{*}$ contributed equally, co-first authors

+contributed equally, co-second authors

‡corresponding author

\begin{abstract}
:
Kinetoplastids are unicellular eukaryotic parasites responsible for human pathologies such as Chagas disease, sleeping sickness or Leishmaniasis ${ }^{1}$. They possess a single large mitochondrion, essential for the parasite survival ${ }^{2}$. In kinetoplastids mitochondrion, most of the molecular machineries and gene expression processes have significantly diverged and specialized, with an extreme example being their mitochondrial ribosomes ${ }^{3}$. These large complexes are in charge of translating the few essential mRNAs encoded by mitochondrial genomes ${ }^{4,5}$. Structural studies performed in Trypanosoma brucei already highlighted the numerous peculiarities of these mitoribosomes and the maturation of their small subunit ${ }^{3,6}$. However, several important aspects mainly related to the large subunit remain elusive, such as the structure and maturation of its ribosomal RNA ${ }^{3}$. Here, we present a cryo-electron microscopy study of the protozoans Leishmania tarentolae and Trypanosoma cruzi mitoribosomes. For both species, we obtained the structure of their mature mitoribosomes, complete rRNA of the large subunit as well as previously unidentified ribosomal proteins. Most importantly, we introduce the structure of an LSU assembly intermediate in presence of 16 identified maturation factors. These maturation factors act both on the intersubunit and solvent sides of the LSU, where they refold and chemically modify the rRNA and prevent early translation before full maturation of the LSU.
\end{abstract}

\section{Introduction}

Kinetoplastids are unicellular eukaryotic parasites, causative agents of several human and livestock pathologies ${ }^{1}$. They are potentially lethal, affecting more than 20 million people worldwide ${ }^{1}$. In part due to their parasitic nature, they strongly diverged from other eukaryotic model species. Kinetoplastids evolved to live in and infect a large variety of eukaryotic organisms in very different molecular environments. Consequently, beyond the general similarities, kinetoplastids species have diverged evolutionarily from each other and their protein sequence identity can be relatively low ${ }^{7}$. They possess a single large mitochondrion, a crucial component of their cellular architecture, where gene expression machineries have also largely diverged, notably their mitochondrial ribosomes (mitoribosomes) $)^{3-5,8-10}$. These sophisticated RNA-proteins complexes translate the few mRNAs still encoded by mitochondrial genomes. The mitoribosomes composition and structure greatly diverged from their bacterial ancestor, with the most extreme case described to date being in fact the kinetoplastids mitoribosomes. With highly reduced rRNAs, and more than 80 supernumerary ribosomal proteins (r-proteins) compared to bacteria, completely reshaping the overall ribosome structure. Recent structural studies performed in Trypanosoma brucei have highlighted the particularities of this mitoribosome structure and composition as well as the assembly processes of the small subunit $(\mathrm{SSU})^{3,6}$. However, in spite of the very comprehensive structural characterization of the full T. brucei SSU and its maturation, several pivotal aspects related to the LSU remained uncharacterized. For instance, a large portion of the LSU at the intersubunit side, including the whole rRNA peptidyl-transfer centre (PTC) along with several r-proteins where unresolved ${ }^{3}$. Moreover, in contrast to the SSU, nearly nothing is known about the LSU maturation and assembly. More generally, the maturation of the mitoribosomes in all eukaryotic species remains largely underexplored. Here, we present a cryo-EM 
bioRxiv preprint doi: https://doi.org/10.1101/2020.05.02.073890; this version posted June 30,2020 . The copyright holder for this preprint (which was not certified by peer review) is the author/funder, who has granted bioRxiv a license to display the preprint in perpetuity. It is made available under aCC-BY-NC-ND 4.0 International license.

investigation of the full mature mitoribosomes from two different kinetoplastids, Leishmania tarentolae (L. tarentolae) and Trypanosoma cruzi ( $T$. cruzi). Most importantly, we reveal the structure of an assembly intermediate of the LSU displaying unprecedented details on rRNA maturation in these very singular mitoribosomes, some of which can probably be generalized to the maturation of all rRNA.

In order to obtain high-resolution reconstructions of the full kinetoplastids mitoribosomes, we purified mitochondrial vesicles from both $L$. tarentolae and $T$. cruzi, and directly purified the mitoribosomes from sucrose gradient (see Methods). All of our collected fractions were analyzed by nano-LC MS/MS (Extended Data Table 1 and 2) in order to determine their proteomic composition. We collected micrographs from multiple vitrified samples corresponding to different sucrose-gradient density peaks for both species and following image processing we obtained cryo-EM reconstructions of the full mitoribosomes, but also the dissociated SSU. Most importantly, we also derived reconstructions of what appeared to be an assembly intermediate of $L$. tarentolae LSU. After extensive rounds of $2 \mathrm{D}$ and $3 \mathrm{D}$ classification and refinement we obtained the structure of $L$. tarentolae and $T$. cruzi complete and mature mitoribosomes at $3.9 \AA$ and $6 \AA$, respectively (Extended Data Figs. 1, 2 and 3). Other notable features include the intersubunit contacts and two distinct rotational states in $T$. cruzi. Similarly to $T$. bruce ${ }^{3}$, our cryo-EM analysis revealed a reconstruction of an early initiation complex from T. cruzi at 3.1 and $3.2 \AA$ for the body and the head of the SSU, respectively (Extended Data Fig. 4). Further focused refinement on the LSU, SSU head and SSU body generated reconstructions at 3.6, 3.8 and $4 \AA$, respectively for $L$. tarentolae (Extended Data Figs. 1 and 2), and 3.7 and $4.5 \AA$ for T. cruzi LSU and SSU, respectively (Extended Data Fig. 3). Combined, these reconstructions, along with the mass-spectrometry data allowed to build nearly complete atomic models, with only few protein densities still remaining unidentified.

\section{General description of mature kinetoplastids mitoribosomes}

Even though $T$. cruzi and $L$. tarentolae proteins are of relative modest sequence identity ( 70\%) for such closely related species ${ }^{7}$, the tertiary structures of the r-proteins and rRNAs as well as the overall structure of the mitoribosomes were nearly entirely identical (Extended Data Fig. 3). Both ribosomes are large complexes mainly formed by proteins (Fig. 1 and Extended Data Fig. 3), 68 in the LSU and 54 in the SSU (Extended Data Table 3), rRNA constituting only 15\% of the total mass. The SSU was reconstructed to high resolution and appears similar to what was previously observed ${ }^{3,6}$. We obtained reconstructions of the latter in the context of the full ribosomes from $L$. tarentolae and $T$. cruzi, but also dissociated in the context of what appears to be a partial initiation complex from $T$. cruzi, bound to mtIF3, which accumulated naturally in our samples (Fig. 1 and Extended Data Fig. 4). In the presence of mt-IF3, the 9S rRNA, in particular the highly reduced helix 44, and uS12m are clearly stabilized. However, in the context of the full ribosome, mt-IF3 is no longer present and the 9S rRNA along with $\mathrm{uS} 12 \mathrm{~m}$ at the subunit interface are significantly more flexible resulting in a scanter resolution. Moreover, for the $T$. cruzi mitoribosome reconstruction, two distinct rotational states are observed, strongly suggesting a fully assembled mitoribosome structure capable of undergoing different conformational states (Extended Data Fig. 3). In contrast to what is observed in prokaryotes and other mitoribosomes, very few of the intersubunit bridges are strictly conserved and most of them rely on protein-protein interactions. However, most of the observed intersubunit bridges are spatially conserved as compared to other known ribosomes but involve here kinetoplastid-specific r-proteins. (Extended Data Fig. 5).

The reconstruction of the large subunit derived from the full mature ribosome (Fig. 1) allowed us to build the entire 12S rRNA including domains IV and V at the interface subunit (Figs. 1 b-c and 4), revealing the catalytic PTC, as well as its intertwined interactions with r-proteins. The structure of the domains IV and $\mathrm{V}$ is globally conserved, even when compared to classical prokaryotic ribosomes (Fig. 4). Among the $68 \mathrm{LSU}$ characterized proteins, uL2m, uL14m, and extensions of bL19m, mL68, previously unaccounted for $^{3}$, were visualised and detected by mass-spectrometry (Fig. 2). These proteins and extensions squeeze through the rRNA and stabilize it in a very intricate manner, compared to the classical prokaryotic and cytosolic ribosomes. Surprisingly, compared to what was previously described on the solvent side of the LSU in T. bruce ${ }^{3}$, proteins $\mathrm{mL} 67, \mathrm{~mL} 71, \mathrm{~mL} 77, \mathrm{~mL} 78$ and $\mathrm{mL} 81$, localized close to the peptide channel exit, are absent (Fig. 1 and 2). However, these proteins are present in the assembly intermediate, as described and discussed hereafter.

\section{General description of the LSU assembly intermediate}

During L. tarentolae 3D classification, a class of particles presenting LSU-like features was found to naturally accumulate in our sample (Extended Data Fig. 1). This class is rather distinct from classical LSU classes observed previously. After refinement and post-processing, this class resulted in a $3.4 \AA$ reconstruction of the complex (Fig. 1). This reconstruction, when compared to the mature LSU, allowed us to visualize significant differences. Indeed, a large portion of the 12S rRNA appears to be 
bioRxiv preprint doi: https://doi.org/10.1101/2020.05.02.073890; this version posted June 30,2020 . The copyright holder for this preprint (which was not certified by peer review) is the author/funder, who has granted bioRxiv a license to display the preprint in perpetuity. It is made available under aCC-BY-NC-ND 4.0 International license.

unfolded, or at least highly flexible at the intersubunit face (Fig. 4). In addition, large well resolved protein densities were observed occupying the position of the rRNA at this region. Moreover, the whole central protuberance (CP) is missing and several additional protein densities were observed on the solvent side (Fig. 1 e-f). Therefore, it clearly appeared that this complex corresponds to an LSU assembly intermediate. Our cryo-EM reconstructions, along with the MS/MS analysis, allowed us to build an atomic model of this LSU assembly intermediate (Fig. $2 \mathrm{~d}$-e). Compared to the mature LSU, this assembly intermediate lacks 18 core r-proteins but includes 16 maturation factors (including $\mathrm{mL67}$, $\mathrm{mL} 71, \mathrm{~mL} 77, \mathrm{~mL} 78$ and $\mathrm{mL} 81$ that were previously described as r-proteins $\left.{ }^{3}\right)$. On the interface, domain IV of the 12S rRNA appears unfolded and several portions of the rRNA undergo refolding or modifications.

\section{Solvent side}

On the solvent side, close to the peptide channel exit, a crown of proteins composed of $\mathrm{mL} 67$, $\mathrm{mL} 71, \mathrm{~mL} 77, \mathrm{~mL} 78$ and $\mathrm{mL} 81$ was observed in the assembly intermediate (Fig. 3), but not on the full mature mitoribosome. The analysis of their structure and interaction network can suggest two main roles. Parts of them hold the 3' and 5' extremities of the 12S rRNA. Indeed, the 5' end of the 12S rRNA is surrounded by several positively charged residues of $\mathrm{mL} 67$ coordinating and stabilizing this extremity (Fig. 3 a). On the 3' end, $\mathrm{mL} 67$ again, with the help of $\mathrm{mL} 81$ as well as r-proteins bL $17 \mathrm{~m}$ and $\mathrm{mL} 85$, stabilize this extremity that is more flexible in the mature LSU (Fig. 3 b), as suggested by its scanter density in the latter. Hence, in the context of the assembly intermediate, these proteins, mainly $\mathrm{mL} 67$, hold both 12S rRNA extremities, most likely stabilizing the rRNA in its r-protein shell during its maturation.

Moreover, next to the rRNA extremities, the peptide channel exit is entirely remodeled compared to the mature LSU, as proteins $\mathrm{mL} 71, \mathrm{~mL} 77, \mathrm{~mL} 78$ reshape the peptide exit. These proteins slightly extend and split the channel exit in two parts (Fig. $3 \mathrm{c}$ ). However, the channel itself is completely blocked by the $\mathrm{N}$-terminal part of $\mathrm{mL} 71$, which therefore would prevent active translation (Fig. $3 \mathrm{~d}$ ), similarly to $\mathrm{mL} 45$ that prevents translation until the mitoribosome is bound to the mitochondrial inner membrane in mammals ${ }^{11}$. Upon maturation, these factors are disengaged, and a classical peptide channel is restored, similar in structure to bacterial ribosomes (Fig. $3 \mathrm{c}-\mathrm{d}$ ). Hence, we hypothesize that these proteins, previously observed in $T$. bruce ${ }^{3}$, are actually maturation factors and that the LSU reconstruction of $T$. brucei is more likely to be a late assembly intermediate (Fig. 7 b). Upon their dissociation from the mature LSU, a novel protein that we termed $\mathrm{mL} 109$ replaces $\mathrm{mL} 67$ and marks the maturation of this region (Fig. 3).

\section{Intersubunit side}

On the intersubunit side, a large portion of the 12S rRNA, corresponding to domain IV, appears unfolded and several proteins occupy its position, acting on the immature domain V. Based on our cryoEM reconstructions coupled with MS/MS analysis and structural and sequence homologies, 11 factors were identified bound to the intersubunit side (Fig. 5). We termed these proteins "mt-LAFs" for mitochondrial LSU assembly factors, consistently with the proposed nomenclature ${ }^{6}$. Some of these factors belong to the family of GTPases and RNA helicases/isomerases, classic actors of ribosome biogenesis and were observed with their respective ligands and rRNA targets (Fig. 6 e). Others are RNA modification enzymes. Part of these factors exhibit homology with bacterial and eukaryotic maturation factors previously identified. However, most of these ribosome maturation factors have never been structurally captured in an assembly intermediate context.

The first noticeable difference with the mature LSU is the absence of central protuberance (CP). Indeed, 8 proteins composing the CP are missing and some of the surrounding proteins adopt different conformations (Extended Data Fig. 6). In the assembly intermediate, the binding of the CP block is prevented by mt-LAF1 and mt-LAF6 (Fig. $5 \mathrm{a}$ and Extended Data Fig. 6). The factor mt-LAF1 is a DEADbox RNA helicase, where both the catalytic and ATP-binding sites are conserved ${ }^{12}$, and the ATP ligand is clearly observed (Fig. 6 e). It occupies the spatial positions of bL27m, bL31m, bL33m and mL82. The role of this family of helicase proteins is to unwind RNA structures and/or RNA-protein complexes, thus they are highly involved in ribosome maturation. Mt-LAF1 shows similarity with Has1, previously described in yeast pre-60S maturation and with Mss116, involved in yeast mitoribosome maturation 13,14 (Extended Data Fig. 7). Here, it contacts two different segments of the 12S rRNA, the tip of H37 loop (residues 341-346) shifting the whole helix, compared to the mature LSU (Fig. 6e), and a single strand (residues 968-975) that will become part of $\mathrm{H} 88$ from domain $\mathrm{V}$ after its maturation. Thus, mt-LAF1 appears to be involved in the maturation of domain $\mathrm{V}$ rRNA. The second factor, mt-LAF6, is in direct contact with mt-LAF1, but does not contact rRNA. Compared to the mature LSU, it occupies the place of $\mathrm{mL} 38, \mathrm{~mL} 69$ and $\mathrm{mL} 82$. It shows high homology with tRNA pseudouridine synthases, however several 
bioRxiv preprint doi: https://doi.org/10.1101/2020.05.02.073890; this version posted June 30,2020 . The copyright holder for this preprint (which was not certified by peer review) is the author/funder, who has granted bioRxiv a license to display the preprint in perpetuity. It is made available under aCC-BY-NC-ND 4.0 International license.

residues of the active site are not conserved (Extended Data Fig. 8), hinting that the protein has lost its original function here. Its role seems to be a placeholder for CP r-proteins, thus acting together with mtLAF1 to prevent the CP r-proteins premature association. When mt-LAF 1 and 6 are disengaged, the CP r-proteins (composed of 8 proteins) can dock onto the LSU (Extended Data Fig. 6). Moreover, the $\mathrm{mL} 59 / 64 \mathrm{C}$-terminal part that is flexible in the assembly intermediate can contact and stabilize the CP in the mature LSU context.

A large portion of the 12S rRNA is unfolded, which corresponds to the entire domain IV (Fig. 4), and several maturation factors are present in the region that will later be occupied by the rRNA after its maturation, including a triptych of GTPases, mt-LAF3, mt-LAF4 and mt-LAF5 (Fig. $5 \mathrm{c}$ and Extended Fig 9). While some of these GTPase have already been identified in bacteria ${ }^{15,16}$ (Extended Data Table 3 ), this is the first time that they are observed acting together on a maturating ribosomal complex at the reported resolution. GTPases have widespread roles in the cell ${ }^{17}$. These enzymes usually exist in two states, active and inactive, where the transition between the states is triggered by GTP hydrolysis. This results in conformational changes of the enzyme that allow its binding to or release from specific targets. mt-LAF5 has two characteristic G-domains, similarly to its bacterial homologue, EngA, also known as GTPase Der ${ }^{15}$. Its role is crucial for domain IV PTC folding in bacteria, a role that is likely conserved here for mt-LAF5 given that their binding sites are similar. mt-LAF4 is bound to H33-35 and appears here to prevent uL2m association. Mt-LAF3 (homolog to the bacterial GTPase RgbA ${ }^{18}$ ) is in contact with mt-LAF 5 and 2. However, it is the only GTPase that does not make significant contacts with the rRNA (Fig. $5 \mathrm{c}$ ), suggesting that it has either already performed its function, or is still awaiting for its rRNA target (Extended Data Fig. 9 b).

Three RNA modification enzymes were found in the assembly intermediate structure, one pseudouridine synthase (termed "mt-LAF2") and two methyltransferases forming a homodimer (termed "mt-LAF7 $a$ and b"). The protein mt-LAF2 is a pseudouridine synthase D family enzyme that shows high homology with RluD, a bacterial enzyme responsible for the modification of several residues on $\mathrm{H} 69$ in domain IV of 23 S rRNA ${ }^{19,20}$ (Extended Data Fig. 8).In our reconstruction, we clearly observe a uridine residue flipped-out of an RNA regular helix to engage the catalytic core of the enzyme (Fig. $6 \mathrm{~d}$ ). MtLAF7 $a$ and $b$ are RNA 2'O-methyltransferases that belong to the SpoU family, which are enzymes wildly involved in methylation of the 23S rRNA in prokaryotes ${ }^{21,22}$ (Extended Data Fig. 10). They are located at the P-stalk region (Fig. 6 a). Surprisingly, the P-stalk structure in the immature rRNA is radically different compared to its mature form. Indeed, the P-stalk rRNA undergoes drastic structural rearrangements between the immature state, where it is shaped into two adjacent large regular helices (Fig. 6 a), and the mature P-stalk (Fig. 6 c), where it doesn't form any RNA helices. Interestingly, even though the fold is radically different, the immature P-stalk rRNA still spans all the way and interacts with the distal uL $11 \mathrm{~m}$ (Fig. $6 \mathrm{~b}$ ) that retains its position in the mature P-stalk. While the nearby homodimeric factors mt-LAF7.a/mt-LAF7.b are in close proximity to the rRNA, they cannot be unambiguously interpreted to bind it directly. mt-LAF7.a/mt-LAF7.b contact $\mathrm{uL} 11 \mathrm{~m}$ and $\mathrm{mL} 53$ inducing the shift of the P-stalk r-protein block compared to the mature structure. Moreover, several surrounding r-proteins such as $\mathrm{uL} 10 \mathrm{~m}$ or $\mathrm{uL} 16 \mathrm{~m}$ are absent. Mt-LAF7 $\mathrm{a}$ and $\mathrm{b}$ are most likely the homologs of the NHR SpoU described in S. actuosus ${ }^{21}$, which are involved in an adenine methylation in H43 of the P-stalk. Due to their position in our assembly intermediate, it is possible that they modify the P-stalk rRNA. The latter will thus be reshaped into its mature structure afterwards, probably under the action of a helicase analogue to mt-LAF1 (Extended Data Fig. 7 c).

Lastly, a complex formed by three assembly factors is found bound to $\mathrm{uL} 14 \mathrm{~m}$, close to the Pstalk. This complex is formed by mt-LAF8, directly contacting uL14m and the tip of H95 (residues 11331136), mt-SAF32 and mt-LAF9 (Fig. $5 \mathrm{~b}$ and 7 a). This complex is nearly identical to the MALSU1:LOR8F8:mt-ACP complex observed in the human mitoribosome LSU assembly intermediate ${ }^{23}$. Indeed, each factor shows high homology to their mammalian homologs, mt-LAF9 corresponding to LOR8F8, mt-SAF32 to mt-ACP and finally mt-LAF8 to MALSU1. The latter shows high homology to the conserved and well characterized bacterial ribosome silencing factor (RsfS) (Fig. 7 e). RsfS is known to prevent premature subunit association during diminished nutrient availability, a molecular mechanism mimicked by elF6 in eukaryotes ${ }^{24,25}$. However, in mitoribosomes, as shown in human, the RsfS homolog alone is not able to prevent subunit association and the anti-subunit association activity can only be achieved in the presence of mt-SAF32 and mt-LAF9.

\section{Discussion}

We describe the structures of the full kinetoplastids mitoribosomes from $L$. tarentolae and $T$. cruzi. These reconstructions allowed us to characterize the complete 12S rRNA of the large subunit revealing notably the yet uncharacterized domain IV and V including the PTC. While kinetoplastids mitoribosomes represent one of the most extreme cases of rRNA reduction ${ }^{6,26}$, these regions are 
bioRxiv preprint doi: https://doi.org/10.1101/2020.05.02.073890; this version posted June 30, 2020. The copyright holder for this preprint (which was not certified by peer review) is the author/funder, who has granted bioRxiv a license to display the preprint in perpetuity. It is made available under aCC-BY-NC-ND 4.0 International license.

structurally conserved compared to bacterial and other mitochondrial ribosomes (Fig. 4). These rRNA domains represent part of the conserved functional core of the ribosome, where the peptidyl transfer is catalyzed, in addition of being a conserved binding surface to the small subunit ${ }^{27}$.

On the small ribosomal subunit, the 9S rRNA appears to be more flexible than its counterpart LSU 12S rRNA, as indicated by its scanter densities at the intersubunit face (Fig. 1). It is important to highlight that the entire SSU 9S rRNA only conserves a reduced number of secondary structures (10 helices $^{3}$ ) and most of its nucleotides are organized in single strands that are intertwined with the $r$ proteins. In our study, its structure was derived from the SSU/mt-IF3 complex where the 9S rRNA densities are solid and interpretable, corroborated by previous studies ${ }^{3,6}$. The reason of the accumulation of these SSU/mt-IF3 complexes is unclear but could reflect a relative low level of translation initiation in $T$. cruzi, at least at the growth stage at which the parasites were harvested. An additional explanation could be the fairly high hydrophobicity index of uS12m that is one of the only two r-proteins (along with uS3m) encoded by the mitochondrial genome in kinetoplastids. Indeed, recruiting such a hydrophobic r-protein to the negatively charged rRNA surface may require the presence of mtIF3 that stabilizes it on the SSU intersubunit face rRNA (Extended Data Fig. 4). In such case, these SSU/mt-IF3 complexes would correspond to a small subunit ready to initiate translation. The biological rational for the presence in kinetoplastids mitoribosomes of such a hydrophobic r-protein (uS12m) embedded in the rRNA at this strategic region remains to be unveiled but could be related to the regulation of the nuclear-mitochondrial crosstalk.

We also describe an assembly intermediate of the large subunit of $L$. tarentolae mitoribosome. Assembly intermediates in mitoribosomes have only been structurally characterized in mammals for the $\mathrm{LSU}^{23}$ and in T. brucei for the SSU ${ }^{6}$. Here, our reconstruction enabled the identification of 16 proteins factors involved in various ways in the LSU maturation. A portion of these factors appears to be conserved in bacteria while the rest are specific to kinetoplastids mitoribosome. The kinetoplastidspecific factors are found on a region of the LSU that has evolutionally diverged the most in terms of structure, i.e. on the solvent-side of the LSU. The positions and interactions of these factors suggest two main roles. First, they maintain the partially unfolded and maturing rRNA 3' and 5' extremities in the LSU protein shell till the complete maturation of the 12S rRNA (Fig. 3). Second, they prevent any premature translation by blocking the peptide channel exit. This molecular mechanism is a known feature of immature LSU/ribosome. For instance, during cytosolic 605 maturation the Rei1 protein probes and clots the nascent peptide tunnel ${ }^{28}$. Another example can be found in the human mitoribosome where $\mathrm{mL} 45$ similarly blocks the channel till the binding to the inner mitochondrial membrane ${ }^{11}$.

The other maturation factors have homologs found in bacterial, cytosolic and mitochondrial ribosome biogenesis processes. They act on the intersubunit side of the LSU where the 12S rRNA is mostly conserved and to some extent similar to bacteria. Amongst these conserved factors, three modification enzymes, two 2'O-methyltransferase (mt-LAF7 a and b) and one pseudouridine synthase (mt-LAF2). The global structures and active sites of mt-LAF 7 and 2 are conserved (Extended Data Fig. 8 and 10). Mt-LAF7 a and b are RNA 2'O-methyltransferases that belong to the SpoU family. Compared to the bacterial enzymes, their structure as well as their dimerization are conserved. Their catalytic core, involved in SAM binding, is conserved as well as their $\mathrm{N}$-terminal domain, involved in dsRNA binding (Extended Data Fig. 10). In the assembly intermediate, mt-LAF7 a and b are located near to three possible targets, H95 and the two helices of the immature P-stalk. Several of these enzymes are involved in methylation of the 23S rRNA in prokaryotes ${ }^{21,22}$. The NHR SpoU described in S. actuosus ${ }^{21}$, are involved in an adenine methylation in H43 of the P-stalk. Given that mt-LAF7 a and b are located close to the P-stalk, it is possible that their target is similar to NHR SpoU. The folding of the immature P-stalk in two helices would therefore be crucial for mt-LAF7 a and b to recognize their target and perform methylation. The protein mt-LAF2 is a pseudouridine synthase $D$ family enzyme that shows high homology to RluD, a conserved bacterial enzyme responsible for the pseudouridylation of several residues on $\mathrm{H} 69$ in domain IV of $23 \mathrm{~S}$ rRNA $^{19,20}$. This enzyme is highly conserved in all Rlu bacterial enzymes (Extended Data Fig. 8) and is essential for ribosome biogenesis and cell growth in bacteria ${ }^{29}$. In our reconstruction, we clearly observe a uridine residue flipped-out of an RNA regular helix to engage the catalytic core of the enzyme as previously characterized for these enzymes (Fig. $6 \mathrm{~d}$ and Extended Data Fig. 8), strongly suggesting that this factor is catalytically functional.

To date, only few examples of rRNA modifications were characterized in mitoribosomes, the best being described in human ${ }^{30}$. Only three types of modification were identified in the human mitoribosomal rRNA: nucleobase methylation, 2'-O-methylation and pseudouridylation. Given the conservation level of mt-LAF 7 and 2 (Extended Data Fig. 8 and 10) as well as the rRNA regions that they target, it is expected that other modifications found in bacteria ${ }^{31}$ and mitoribosomes ${ }^{30}$ in domains IV and V might also be conserved in kinetoplastids mitoribosomes (such as Um2552 in E. coli, equivalent 
bioRxiv preprint doi: https://doi.org/10.1101/2020.05.02.073890; this version posted June 30, 2020. The copyright holder for this preprint (which was not certified by peer review) is the author/funder, who has granted bioRxiv a license to display the preprint in perpetuity. It is made available under aCC-BY-NC-ND 4.0 International license.

to mitoribosome human $\left.U \mathrm{~m} 1369^{30}\right)$. In our reconstruction, we also observed the presence of an inactive pseudouridine synthase, mt-LAF6, as deduced by the lack of conservation of critical catalytic amino acids, compared to bacterial, human and yeast homologs (Extended Data Fig. 7 a). Its location on the LSU assembly intermediate suggests its repurposing as an anti-binding factor, as it interferes with the binding of the central protuberance (Extended Data Fig. 6).

Three GTPases, all homologs of bacterial proteins, are also found in our reconstruction (Extended Data Fig. 9). The bacterial homologs of two of them, EngA (homolog of mt-LAF5) and RbgA (homolog of mt-LAF3) were previously described in context of the $50 \mathrm{~S}^{15,16}$. Mt-LAF5, in the GTP state, (Extended Data Fig. 9 a) interacts with H74-75 of domain $\mathrm{V}$ and mt-LAF3 that contacts mt-LAF5 through its N-terminal domain. Similarly to the described roles of these proteins in bacteria, they bind the assembly intermediate rRNA to facilitate the folding of domain IV and V helices ${ }^{15,16}$. The third GTPase, $\mathrm{mt}-\mathrm{LAF}$, is homologous to EngB/YihA in bacteria that was structurally characterized alone, outside the context of the maturing LSU. Here, we show that in the L. tarentolae LSU assembly intermediate, mtLAF4 contacts helices H33-35 of domain II and occupies the place of uL2m (Extended Data Fig. $9 \mathrm{c}$ ). Finally, the DEAD-box RNA helicase mt-LAF1 is found on the immature H88 (Extended Data Fig. 7). Comparison with other structures of DEAD-box enzymes revealed that, aside from the presence of a flexible insertion domain between the DEAD and helicase domains, the overall organization of the domains is conserved. Ligand and RNA binding are also performed in a conserved fashion. mt-LAF1 is in the closed state of its cycle, acting on a single stranded portion of $\mathrm{H} 88$, confirming its activity. Although the role of the flexible insertion domain between the DEAD and helicase domains is unknown, it does not appear to hamper its function. This factor has no obvious bacterial homologs but shows similarity to $\mathrm{Has}^{14}$ and Mss116 ${ }^{13}$. While Has1 participates in the maturation of $\mathrm{H} 16$ in the pre-60S cytosolic ribosome, Mss116 appears to be mt-LAF1 yeast mitochondrial homolog. The structure of Mss116 was solved alone, off the context of the maturing yeast mitochondrial ribosome ${ }^{13}$. Therefore, our structure provides invaluable insight on the molecular basis of the maturation function of this protein.

Lastly, the mt-LAF8:mt-LAF9:mt-SAF32 complex is composed by the bacteria-conserved Rsfs factor (mt-LAF8) and two repurposed respiratory complex I components (mt-SAF32 and mt-LAF9) ${ }^{32-34}$. The latter are supernumerary subunits of the complex I in eukaryotes, i.e. that they are not part of the core proteins found in bacterial complex $\mathrm{I}^{35}$, but were acquired during respiratory complex I evolution in mitochondria 36,37 . Interestingly, they interact together in the same fashion as in the mitochondrial complex I (Fig. 7 a-e). Moreover, in the T. brucei SSU assemblosome ${ }^{6}$, mt-SAF32 binds mt-SAF31 that possesses a LYR-domain (LYR designate the conserved tripeptide motif Leucine, Tyrosine and Arginine). LYR-domains are characterized by a specific fold made of three antiparallel helices. Mt-LAF9 found in our structure also contains a LYR-domain, thus mt-SAF32 most likely recognize the characteristic LYR fold in order to bind to mt-SAF31 and mt-LAF9 in the context of SSU and LSU assembly intermediates. Even though respiratory chain components in kinetoplastids appear strongly divergent from the rest of eukaryotes ${ }^{38}$, the presence of the mt-LAF9:mt-SAF32 in both human LSU assembly intermediate and complex I, in addition to the presence of mt-SAF32 in kinetoplastids SSU assembly intermediate, suggests a multi-role of these proteins and hint at a possible crosstalk between mitoribosome maturation and respiratory complex assembly. The natural accumulation of the LSU assembly intermediate in our sample could be promoted by the presence of the mt-LAF8:mt-SAF32:mtLAF9 complex, which might be stress-induced or caused by diminished nutrient availability, likewise in bacteria. Interestingly, as its name already indicates, mt-SAF-32 is also found in the SSU assembly intermediates, likewise at a peripheral position of the intersubunit side ${ }^{6}$.

In conclusion, our cryo-EM structures of kinetoplastids mitoribosomes, especially the yet uncharacterized LSU assembly intermediate, shed new lights into ribosome maturation. Even though several proteins are specific to kinetoplastids, most of the maturation factors present in our structure have homologs in other eukaryotes, mitochondria or bacteria (Extended Data Table 3). Hence, our structure unveils the mode of actions of these factors, for which no high-resolution structures in native conditions existed. It also highlights that despite being highly divergent, kinetoplastids mitoribosomes retained several canonical maturation pathways for their rRNAs and probably follow an analogous mechanistic pattern (Fig. $7 \mathrm{f}-\mathrm{g}$ ). Indeed, in concert, a set of factors intercalate with the premature rRNA (GTPases) to mechanically unpack different premature rRNA domains, allowing RNA helicases to disentangle and unwind the rRNA and several families of modification enzymes to access their targets. The remodeling of the rRNA is also aided by the recruitment of the r-proteins early during the maturation process. This is especially true in the kinetoplastids mitochondria, where most of the r-proteins are already recruited at the observed stage and form a thick protein shell holding the rRNA together. At the same time, various anti-association factors prevent premature binding of $r$-proteins and the SSU joining. 
bioRxiv preprint doi: https://doi.org/10.1101/2020.05.02.073890; this version posted June 30, 2020. The copyright holder for this preprint (which was not certified by peer review) is the author/funder, who has granted bioRxiv a license to display the preprint in perpetuity. It is made available under aCC-BY-NC-ND 4.0 International license.

In spite of large environmental and host diversities in which these parasites evolve, their mitoribosomes are conserved structurally among kinetoplastids. Therefore, our structures could serve as a basis for future experiments to develop more effective and safer kinetoplastid-specific therapeutic strategies. Finally, as kinetoplastids undergo extensive mitochondrial reorganization ${ }^{39}$ during their life cycle, both in vectors and hosts, it would also be interesting to study mitoribosomes from different stages of development from the parasite's life cycle. 
bioRxiv preprint doi: https://doi.org/10.1101/2020.05.02.073890; this version posted June 30, 2020. The copyright holder for this preprint (which was not certified by peer review) is the author/funder, who has granted bioRxiv a license to display the preprint in perpetuity. It is made available under aCC-BY-NC-ND 4.0 International license.

.
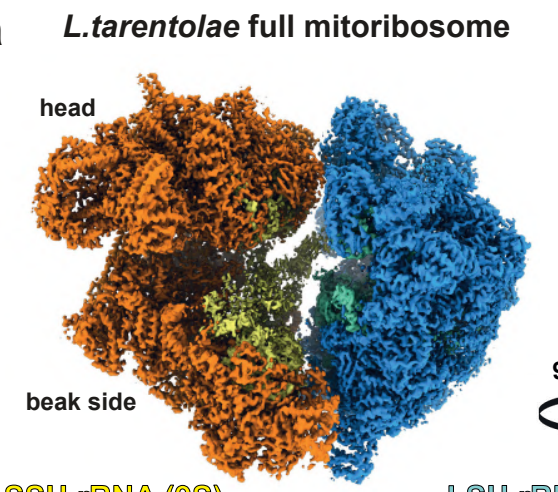

C

Mature LSU
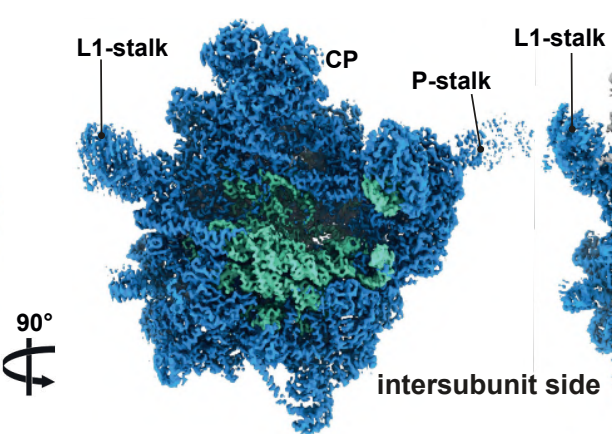

e Assembly intermediate

SSU PRNA (9S)

b

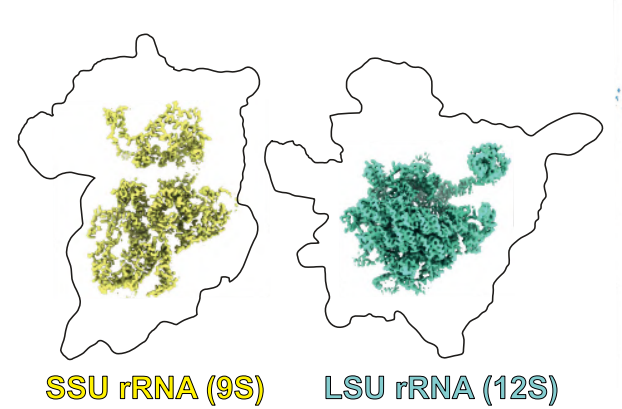

LSU $\mathbb{R} R \mathbb{N}$ (12S)
LSU rproteins
Unidentified densîties

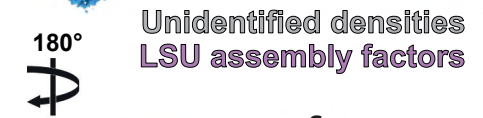

d<smiles>[GeH3]</smiles>

$f$
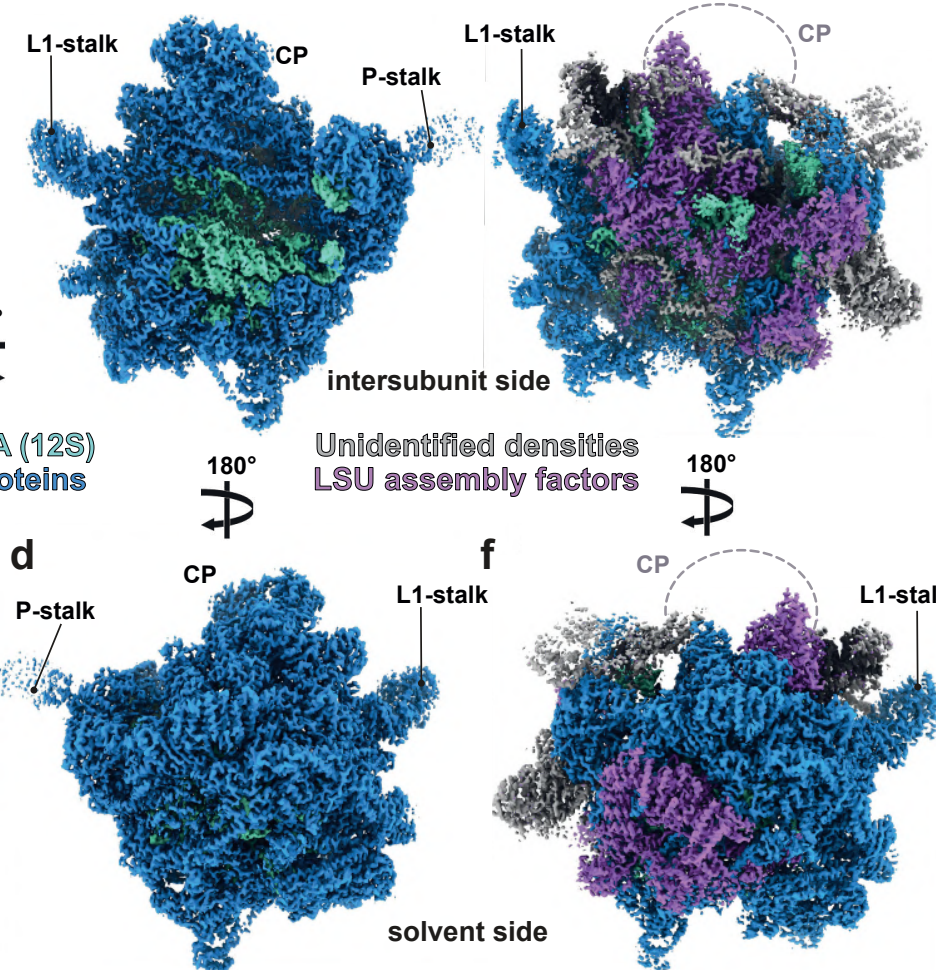

$\stackrel{1800}{P}$

$\mathrm{CP}$

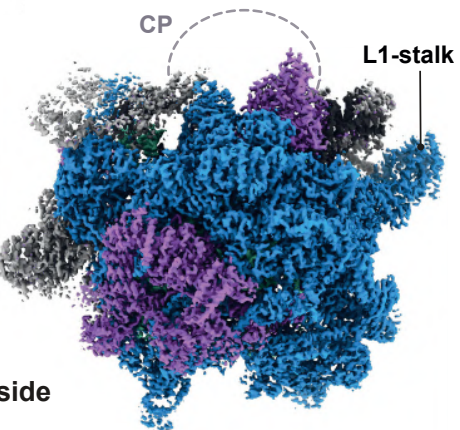

Figure 1. Cryo-EM reconstructions of the mature and assembly intermediate $L$. tarentolae mitoribosome (a) Composite cryo-EM map of the full and mature mitoribosome of $L$. tarentolae. SSU is depicted in orange shades, with proteins in orange and rRNA in yellow and LSU is depicted in blue, with proteins in dark blue and rRNA in aquamarine. (b) Relative sizes of the rRNA (colored segmented densities) compared to that of the r-proteins (presented as thick black contours). (c and d) present the cryo-EM reconstructions of the mature LSU viewed from the intersubunit (c) and solvent (d) side, compared with the LSU assembly intermediate subunit (e-f). Densities corresponding to assembly factors are shown in purple, grey correspond to unidentified factors. 
bioRxiv preprint doi: https://doi.org/10.1101/2020.05.02.073890; this version posted June 30, 2020. The copyright holder for this preprint (which was not certified by peer review) is the author/funder, who has granted bioRxiv a license to display the preprint in perpetuity. It is made available under aCC-BY-NC-ND 4.0 International license.

a

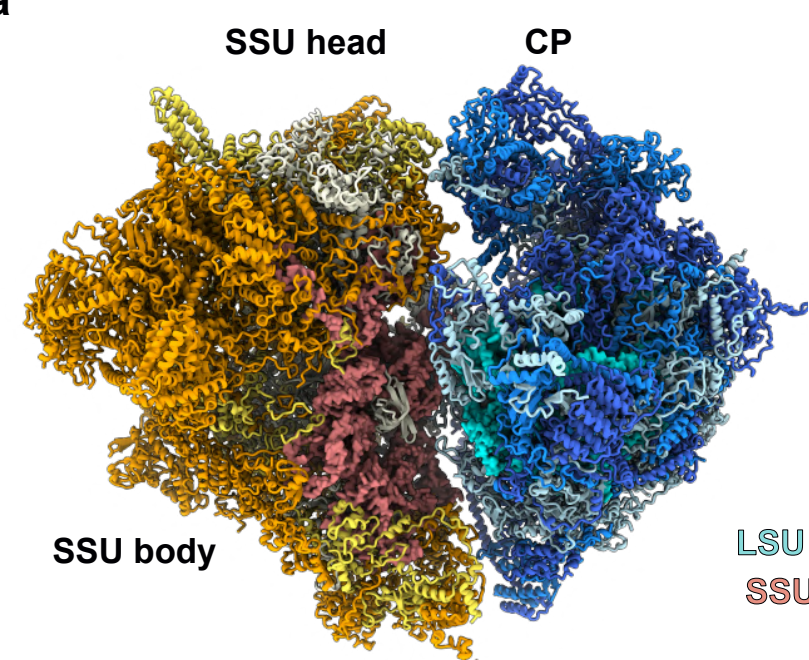

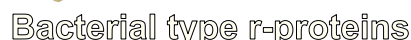

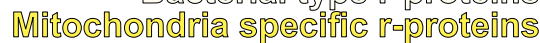
Kinetoplastid specific raproteins
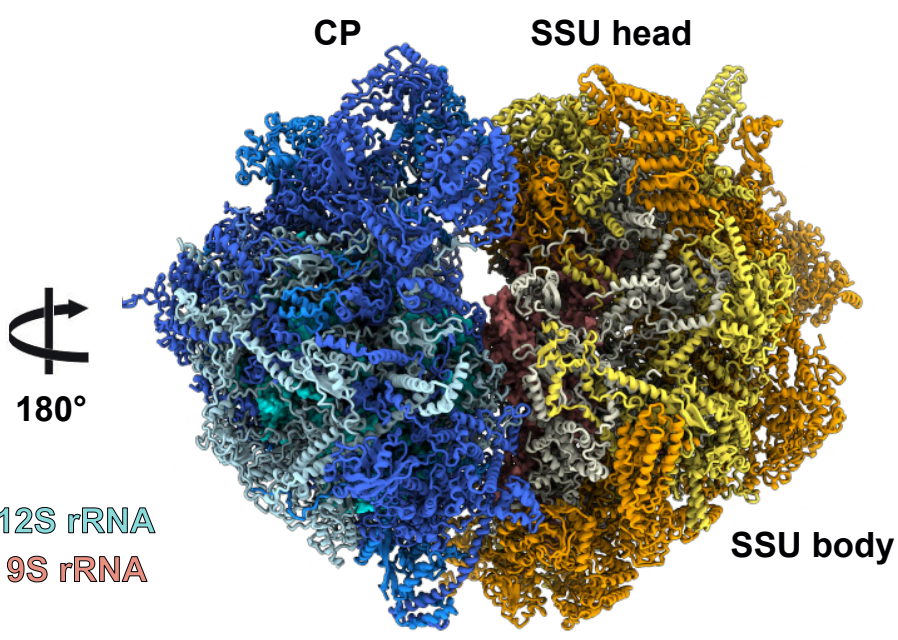

Bล๔

Mitochondria specific r-proteins Kinetoplastid specific r-proteins
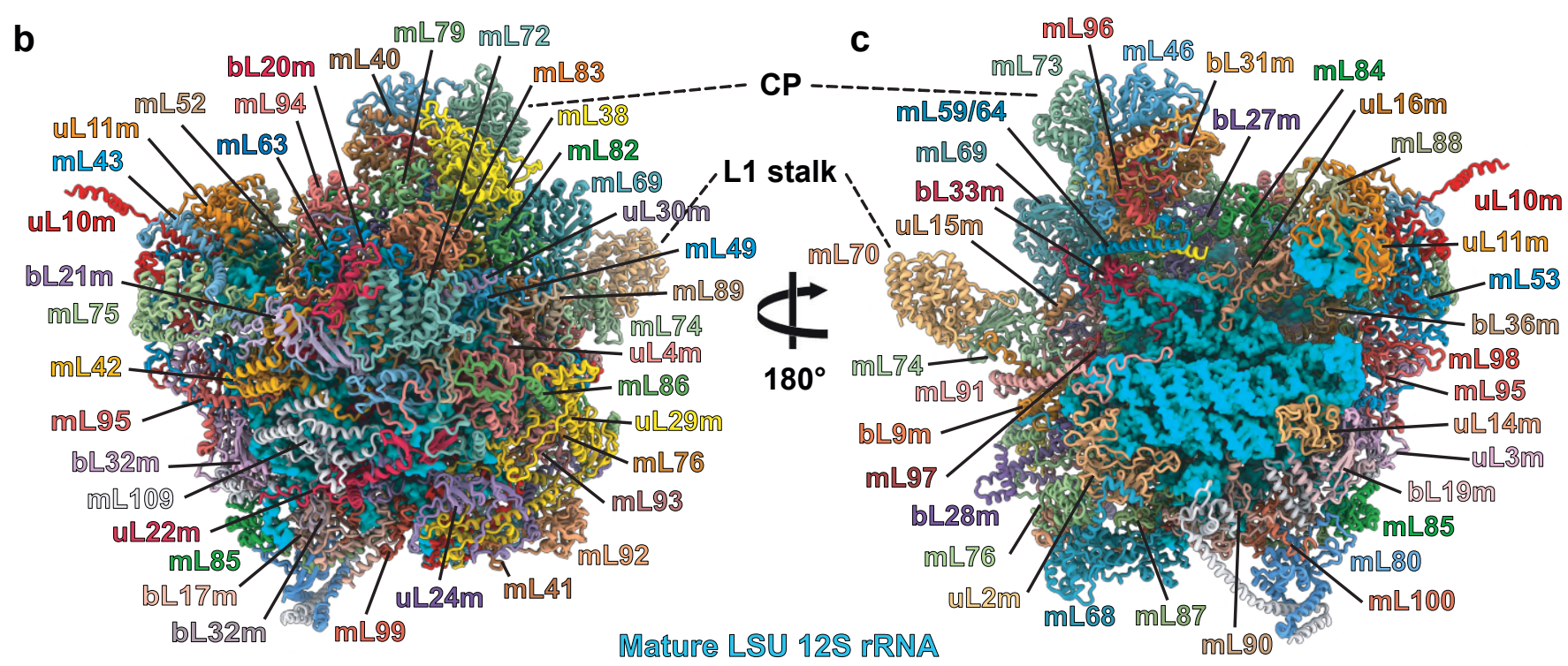

d
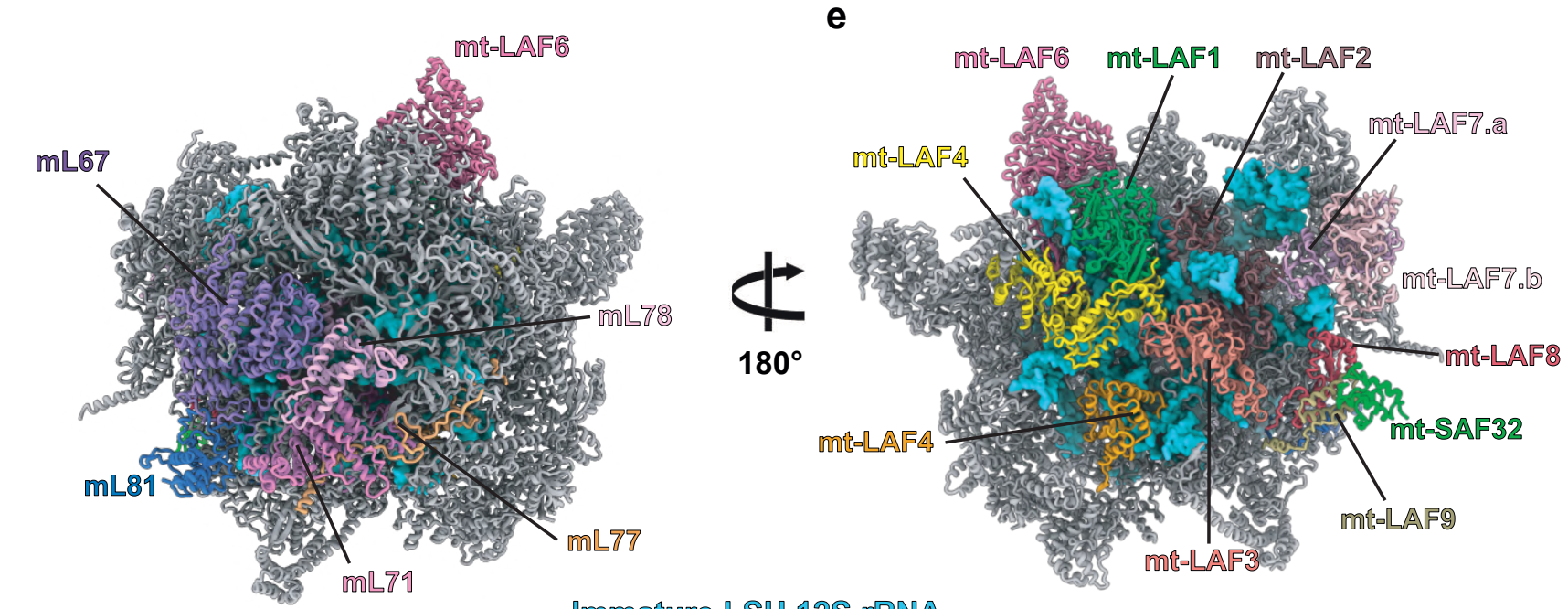

Immature LSU 12S rRNA

Figure 2. Atomic models of $L$. tarentolae mitoribosome and LSU assembly intermediate

(a) Overall model of $L$. tarentolae mitoribosome. 12S rRNA is colored in cyan (LSU) and the 9S rRNA in brick (SSU). Ribosomal proteins are colored in shades of blue (LSU) and shades of yellow (SSU), according to their conservation. Solvent side (b) and intersubunit side (c) of the mature LSU with each individual r-proteins annotated and displayed with a different color. Solvent side (d) and intersubunit side (e) of the LSU assembly intermediate. Conserved proteins in the mature LSU (b-c) are depicted in gray and assembly factors are colored in different shades and individually annotated. 
bioRxiv preprint doi: https://doi.org/10.1101/2020.05.02.073890; this version posted June 30, 2020. The copyright holder for this preprint (which was not certified by peer review) is the author/funder, who has granted bioRxiv a license to display the preprint in perpetuity. It is made available under aCC-BY-NC-ND 4.0 International license.

a
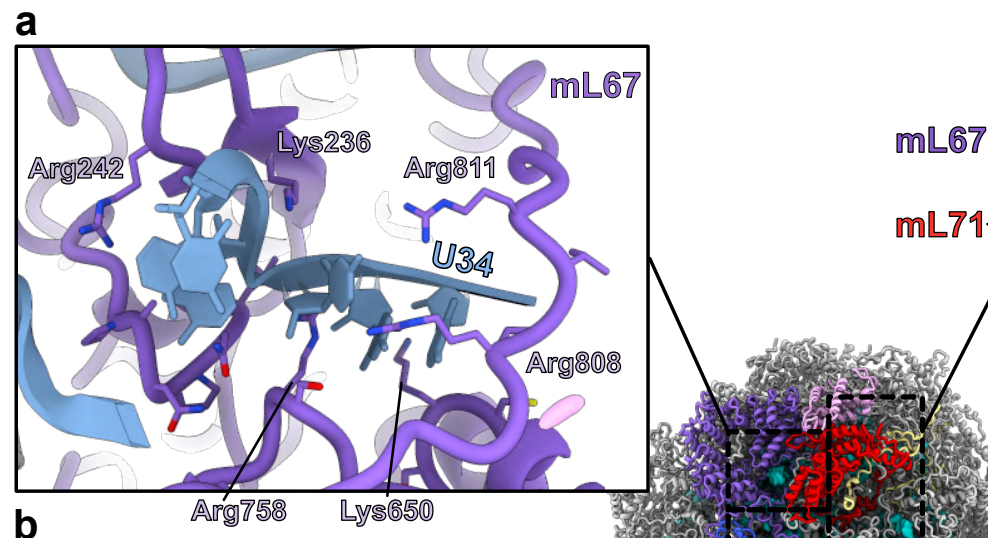

C ஸाட78

Assembly intermediate

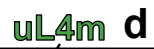

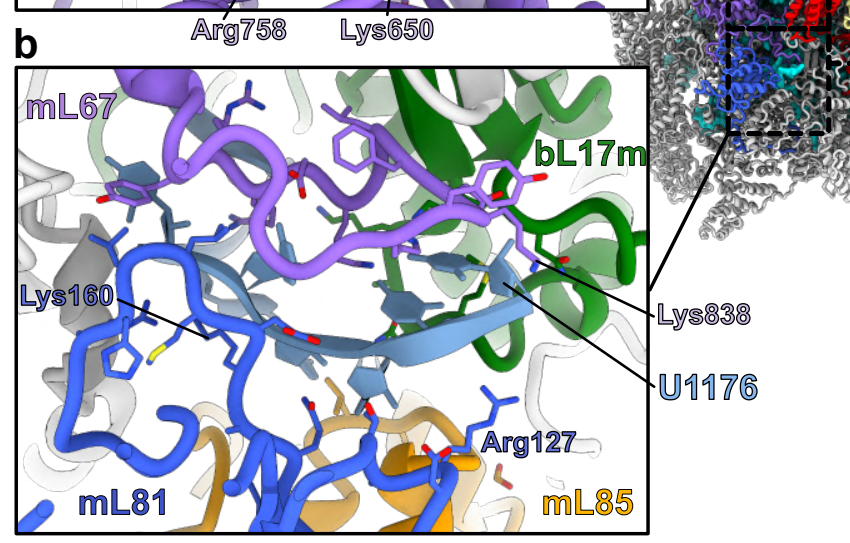

- o तो है
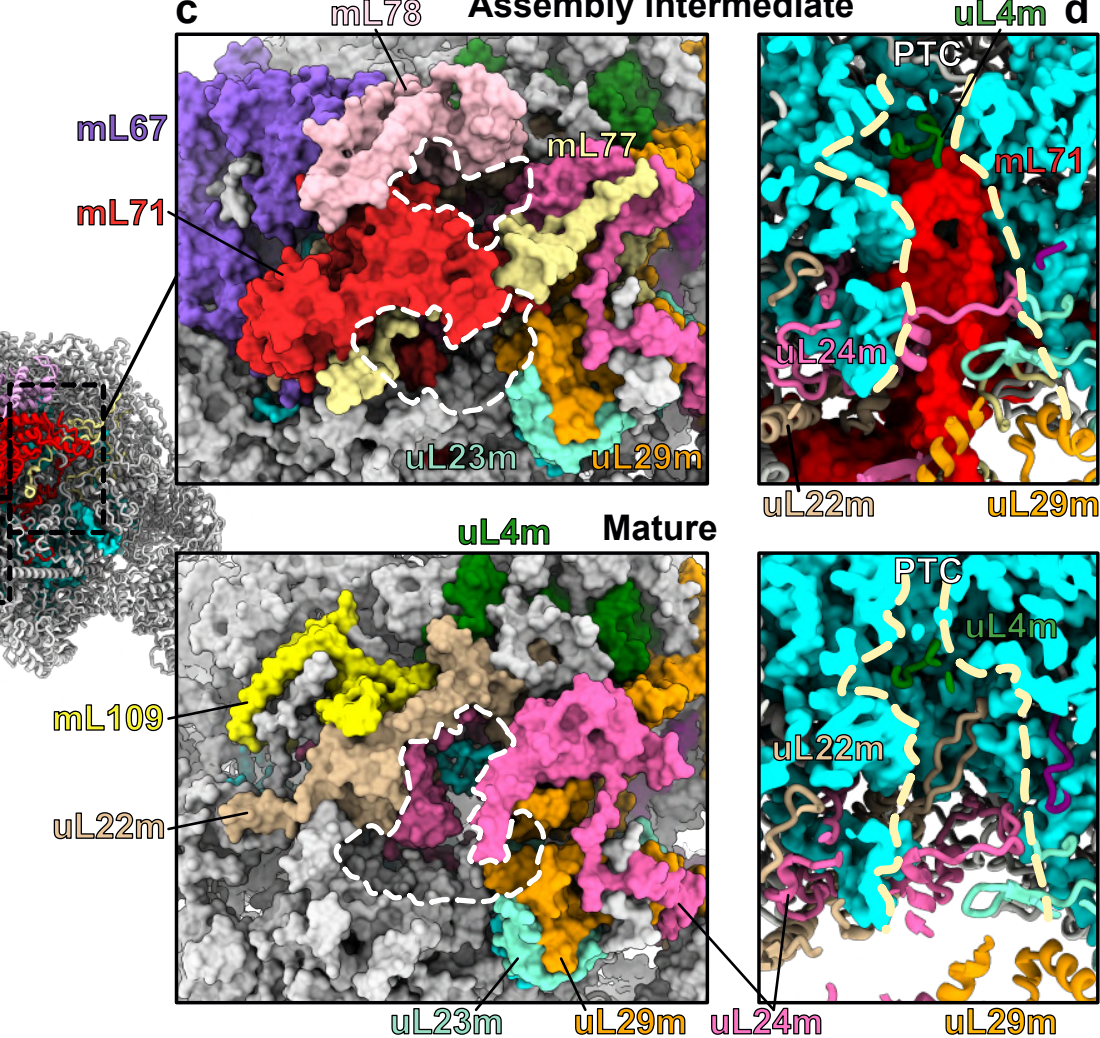

Figure 3. Specific factors hold the 12S rRNA termini and probe the peptide channel exit on the solvent side of the immature LSU

On the solvent side, 5 maturation factors act together to hold the extremities of the rRNA (a-b) and probe the peptide exit channel (c-d). The $12 \mathrm{~S} 5^{\prime}$ termini (a) is held by several positively charged residues of $\mathrm{mL} 67$, and the 3' extremity (b) is stabilized by $\mathrm{mL} 67$ and $\mathrm{mL} 81$ as well as r-proteins $\mathrm{mL} 85$ and bL $17 \mathrm{~m}$. U34 and U1176 indicate the terminal rRNA residues. (c and d) present the peptide channel of the assembly intermediate (top) and mature (bottom) LSU from top (c) and cut view (d). Proteins $\mathrm{mL} 71, \mathrm{~mL} 77, \mathrm{~mL} 78$ reshape the peptide exit channel by slightly extending and splitting it in two in the assembly intermediate compared to the mature LSU (c). Dashed white contours delimit the peptide channel exit orifices in the mature and immature LSU. Maturation factor $\mathrm{mL} 71$ completely blocks the exit channel through its $\mathrm{N}$-terminal domain (d). Dashed yellow lines delimit the peptide channel in the longitudinal axis. 
bioRxiv preprint doi: https://doi.org/10.1101/2020.05.02.073890; this version posted June 30, 2020. The copyright holder for this preprint (which was not certified by peer review) is the author/funder, who has granted bioRxiv a license to display the preprint in perpetuity. It is made available under aCC-BY-NC-ND 4.0 International license.

a

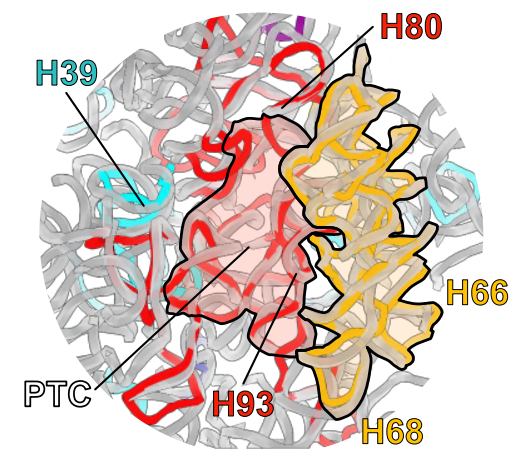

b

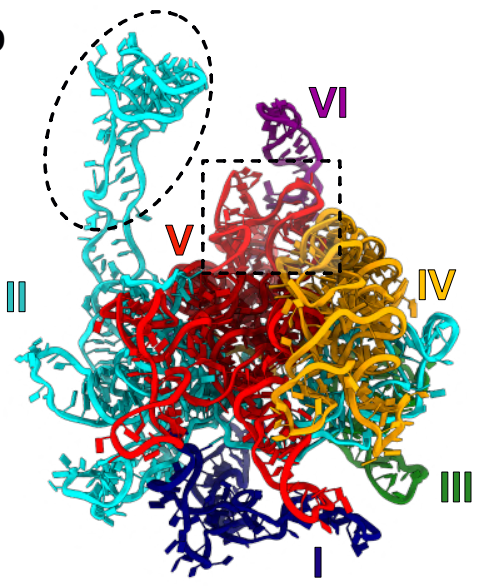

C

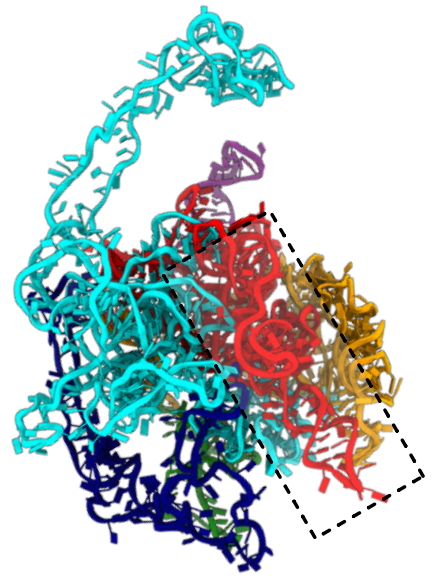

d

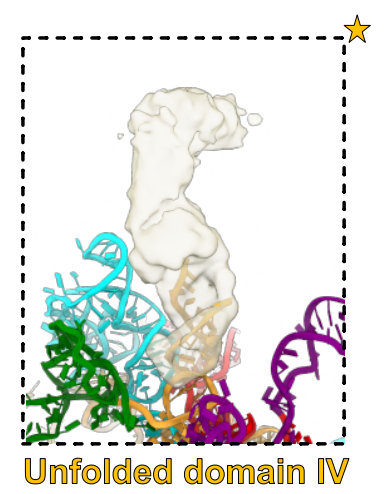

Ilmmature P-stallk Unfolded H90-92

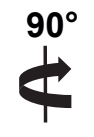

e

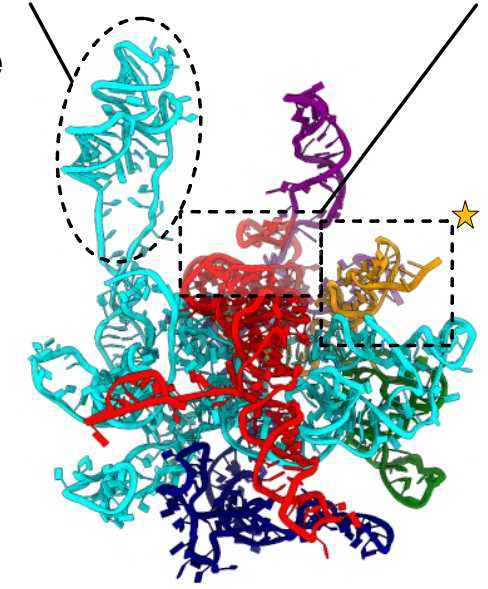

Lifted-up H75
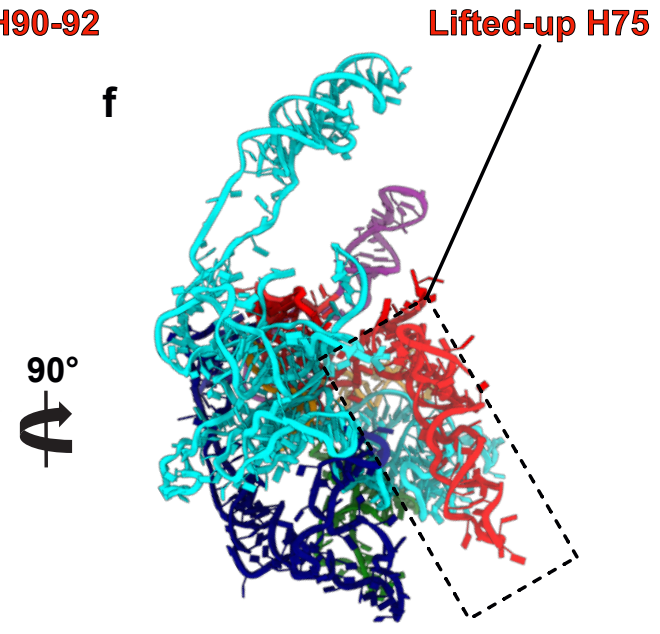

Figure 4. Comparison of the mature and assembly intermediate 12 rRNA

Comparison between mature (a-c) and assembly intermediate (d-f) 12S rRNA. Each rRNA domains are colored differently. The rRNA is presented from the intersubunit view (b-e) and a side view (c-f). (a) Superimposition of the 12S mature rRNA with E. coli 23S rRNA, displayed in gray, shows that the structure of domain IV (orange) and the PTC is highly conserved. Between the mature and assembly intermediate rRNA, the main differences are observed in domain II, where the P-stalk is folded differently, in domain IV which is entirely unfolded (d), and domain V which is unfolded from $\mathrm{H} 90$ to $\mathrm{H} 92$ (e) and where $\mathrm{H} 75$ is entirely lifted-up (f). Most of the maturation factors act on domain $\checkmark$ which is accessible thanks to the unfolded domain IV. 
bioRxiv preprint doi: https://doi.org/10.1101/2020.05.02.073890; this version posted June 30, 2020. The copyright holder for this preprint (which was not certified by peer review) is the author/funder, who has granted bioRxiv a license to display the preprint in perpetuity. It is $\mathbf{a}$ made available under aCC-BY-NC- 6 D 4.0 International license.

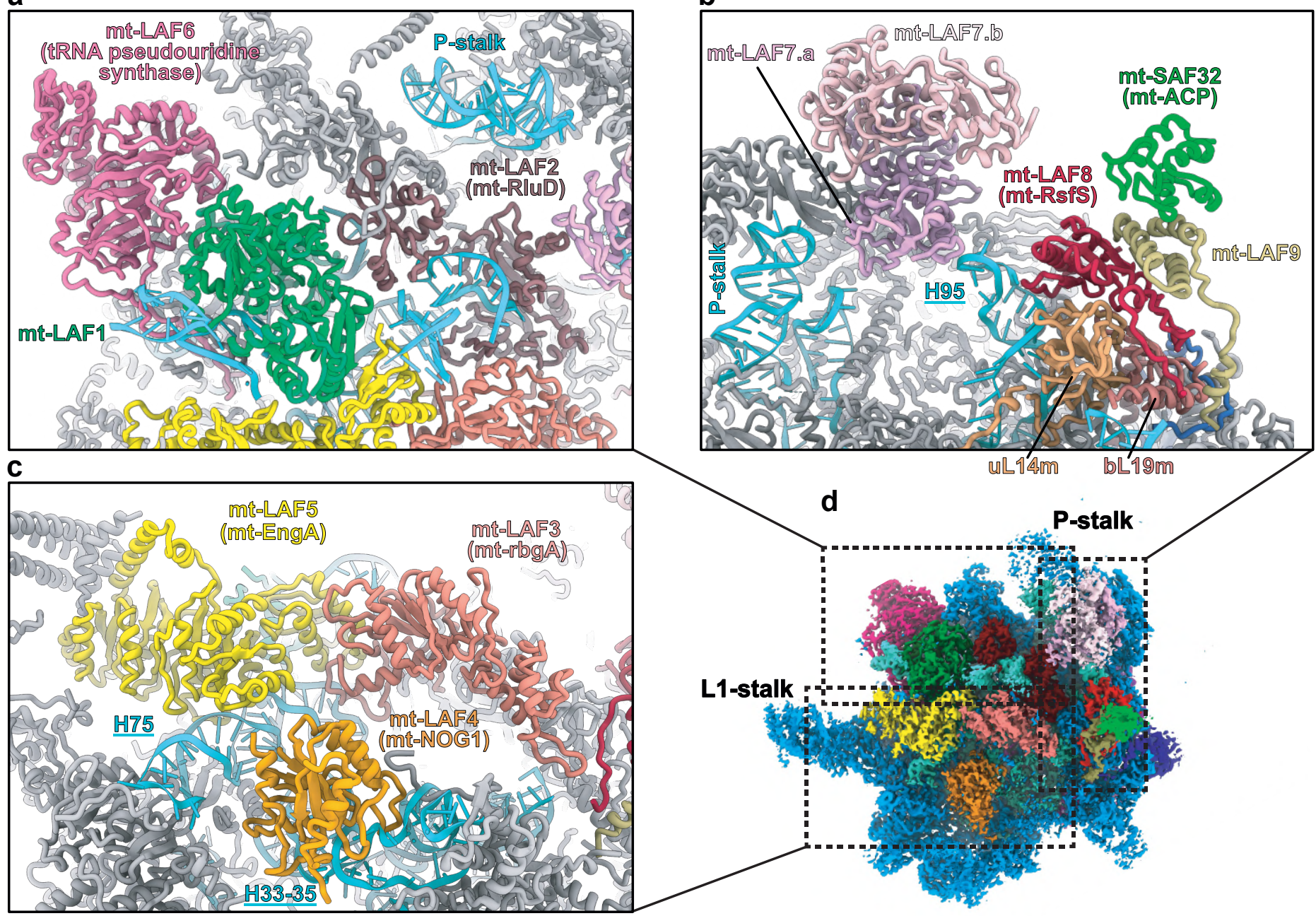

Figure 5. Overall view of the maturation factors on the intersubunit side

On the intersubunit side of the immature LSU, 11 maturation factors act together to remodel and modify the rRNA (d). (a) mt-LAF6 and mt-LAF1 occupy the position of the central protuberance (CP). mt-LAF1 and mt-LAF2 interact with remodeled rRNA. (b) Mt-LAF8 together with mt-LAF9 and mt-SAF32 interact with uL14m and H95 to block the SSU association. (c) Arrangement of the GTPase triptych. The GTPases mt-LAF5 and mt-LAF4 bind respectively the rRNA $\mathrm{H} 75$ and $\mathrm{H} 37$ while mt-LAF3 occupies a central place in the complex and makes a bridge between the GTPases and mt-LAF2 and mt-LAF8. 
bioRxiv preprint doi: https://doi.org/10.1101/2020.05.02.073890; this version posted June 30, 2020. The copyright holder for this preprint (which was not certified by peer review) is the author/funder, who has granted bioRxiv a license to display the preprint in perpetuity. It is a made available unde biCC-BY-NC-ND 4.0 Intecational license.

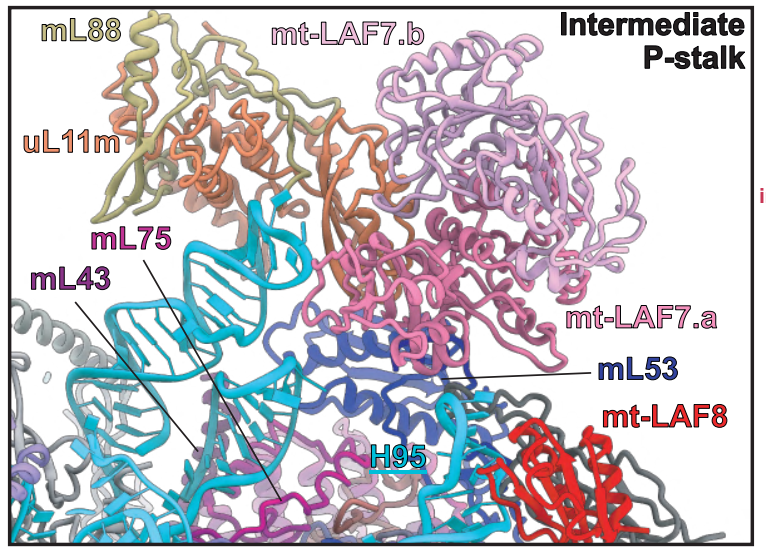

d

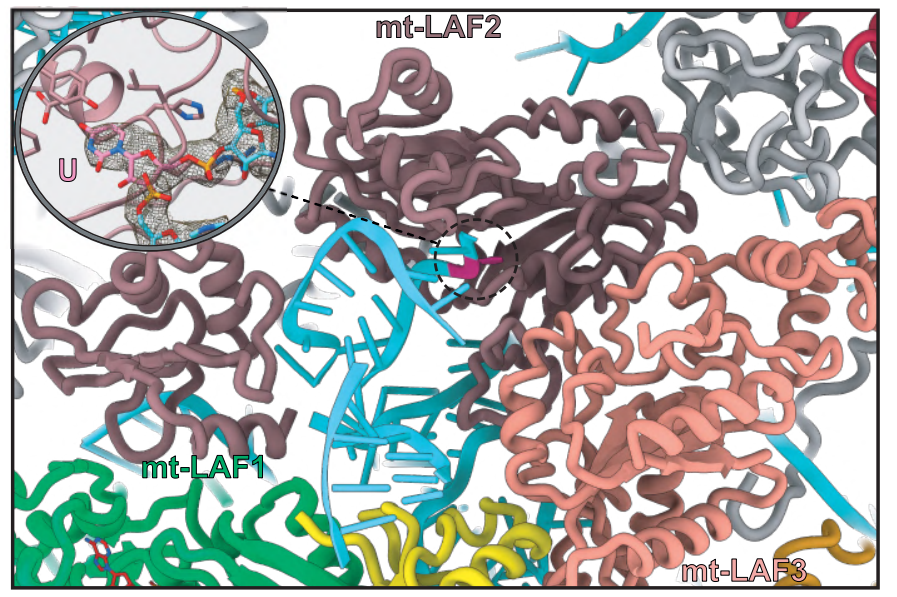

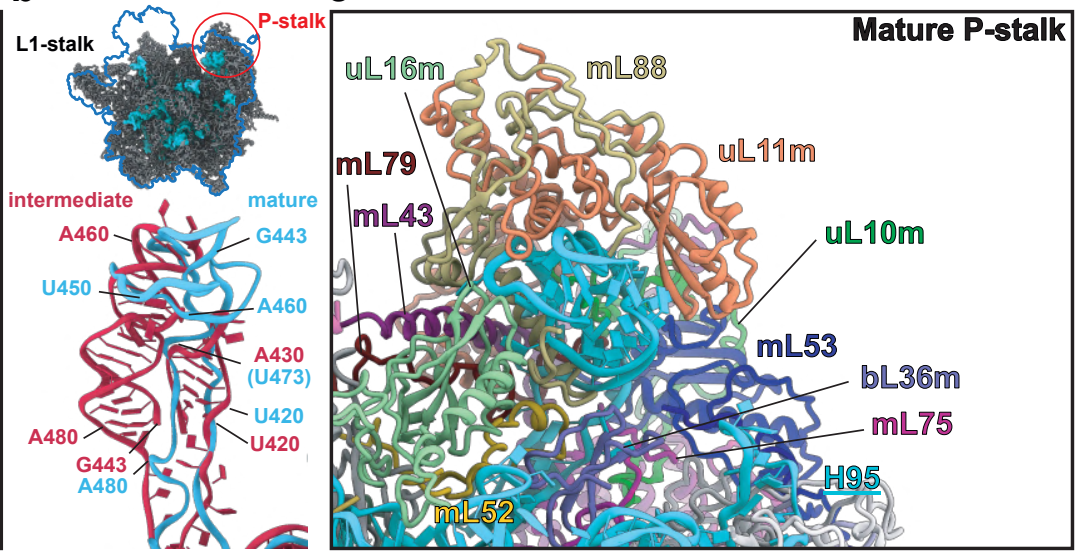

e

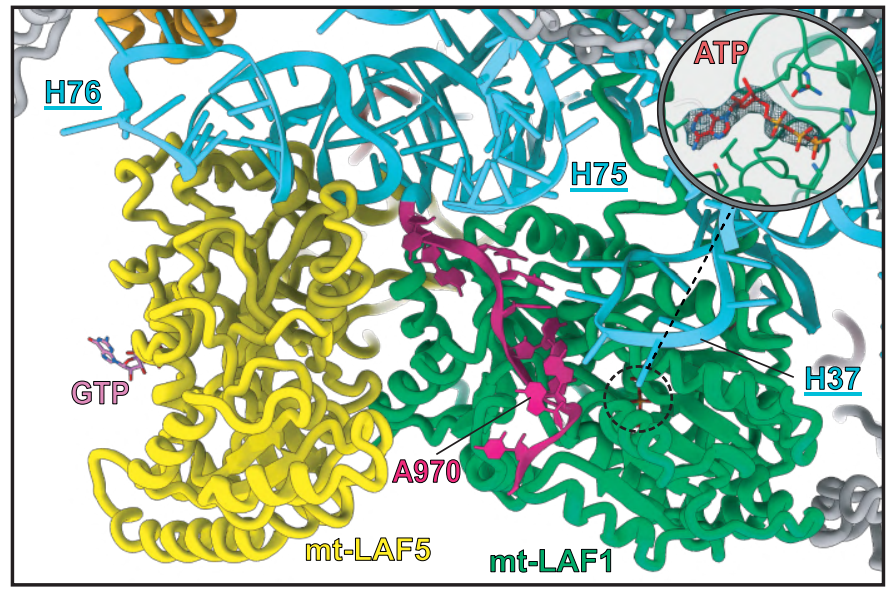

Figure 6. Maturation of the Leishmania mitochondrial LSU rRNA

Details on how maturation factors interact with, and affect the 12S RNA (a) P-stalk region of the intermediate LSU. mt-LAF7 homodimer contacts uL $11 \mathrm{~m}$ and $\mathrm{mL} 53$, the two helices of the immature P-stalk as well as the helix H95 are adjacent to the dimer. (b) Overlap of the two forms of rRNA P-stalk structure, immature in red and mature in blue. (c) P-stalk region of the mature LSU. (d) Insight into the rRNA modification by the pseudouridine synthase mt-LAF2. In order to be catalyzed the rRNA is refolded into a helix structure, probably to be recognized by mt-LAF2, the uridine subtract is flipped out of the helix and engaged in the catalytic core of the enzyme. (e) The two factors mt-LAF5 and mt-LAF1 bind jointly to the rRNA. The dead box helicase mt-LAF1 is in an active state with a single strand RNA of the immature H88, shown in burgundy, in its catalytic core and loaded with an ATP molecule. Doted circle corresponds to magnified region. 
bioRxiv preprint doi: https://doi.org/10.1101/2020.05.02073890. this version nosted_une 30,2020 . The copyright holder for this preprint (which was not certified by peer review) is the autbr/funder, who has granted biबRxiच a license to display the preprint in perpetuity. It is made available under aCC-BY-NC-ND 4.0 Internationa license.
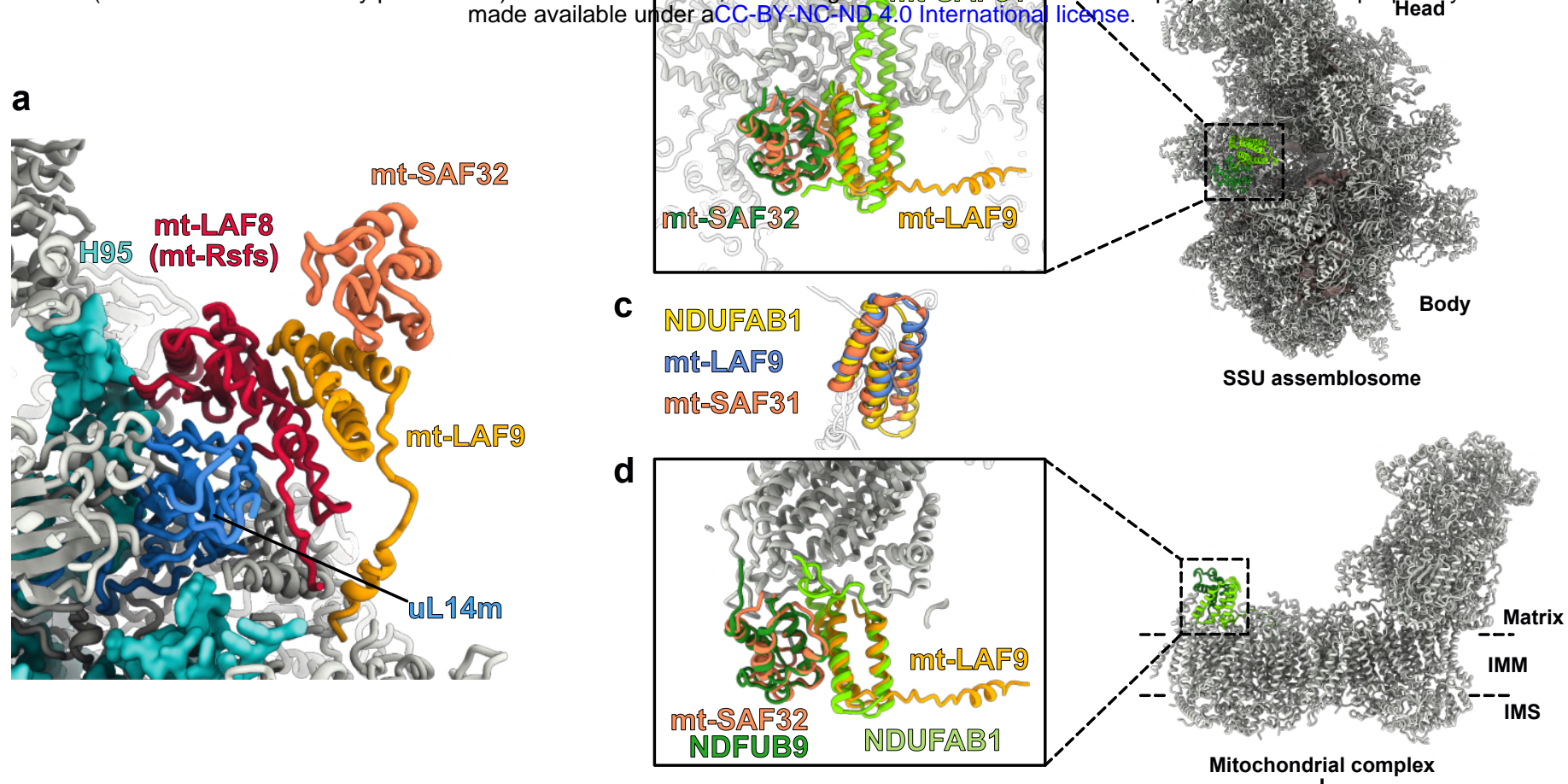

e
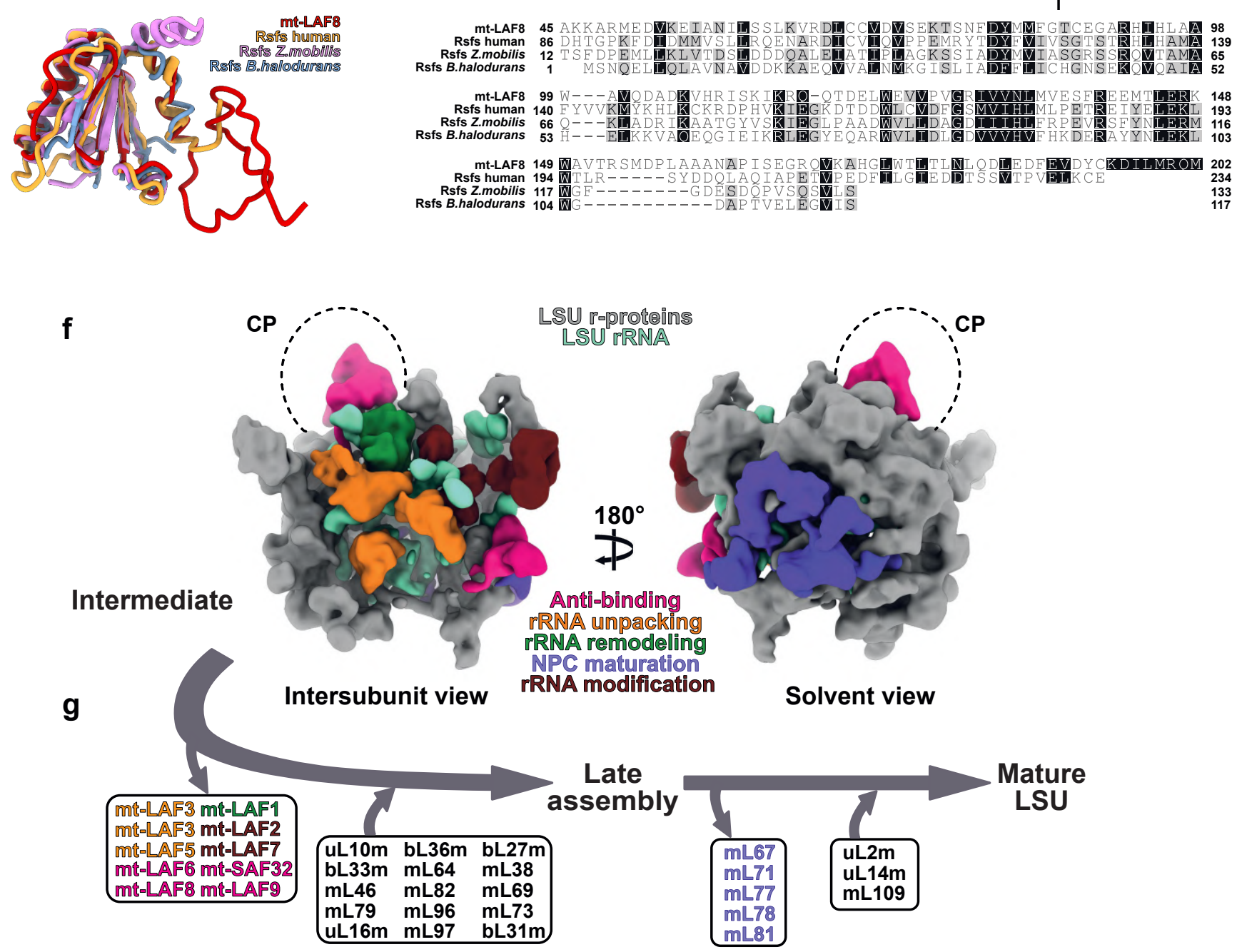

Figure 7. Key factors and schematic view of the stepwise assembly

Zoom on the mt-LAF8:mt-LAF9:mt-SAF32 factors involved in anti-subunit association (a). mt-LAF8 is the homolog of the bacterial protein Rsfs (e) and mt-SAF32 and mt-LAF9 are also found in mitochondrial respiratory complex I as supernumerary proteins. In (b) mt-SAF32 and mt-LAF9 are superimposed with mt-SAF32 and mt-SAF31 found in the SSU assemblosome of T. bruce ${ }^{6}$ (PDB: 6SGB). In (d) mt-SAF32 and mt-LAF9 are respectively superimposed with NDUFB9 and NDUFAB1, here from the yeast mitochondrial complex $\mathrm{I}^{32}$ (PDB: 6RFR), homolog proteins are annotated using the human nomenclature of complex I proteins. mt-LAF9, NDUFAB1, and mt-SAF31 are LYR proteins characterized by the LYR-protein fold (three antiparallel helices) shown in (c). IMM stands for inner mitochondrial membrane and IMS for inter membrane space. In (e), the high structural conservation of Leishmania mt-LAF8 is illustrated by structural superimposition and sequence alignment with the human mitochondrial Rsfs (PDB: 5OOL) as well as two bacterial Rsfs (PDB: 3UPS and 2O5A). (f) Schematic view of the LSU assembly intermediate of $L$. tarentolae presented from the intersubunit and solvent sides. Maturation factors are colored by function. Starting from the LSU assembly intermediate in $(\mathbf{f}),(\mathbf{g})$ details the dissociation of maturation factors and the association of r-proteins, considering the T. brucei $\mathrm{LSU}^{3}$ as a late assembly intermediate. Maturation factors are colored as in (f) and r-proteins are shown in black. 
bioRxiv preprint doi: https://doi.org/10.1101/2020.05.02.073890; this version posted June 30, 2020. The copyright holder for this preprint (which was not certified by peer review) is the author/funder, who has granted bioRxiv a license to display the preprint in perpetuity. It is made available under aCC-BY-NC-ND 4.0 International license.

\section{METHODS}

Methods and any associated references are available in the online version of the paper.

\section{ACKNOWLEDGEMENTS}

This work has benefitted from the facilities and expertise of the Biophysical and Structural Chemistry platform (BPCS) at IECB, CNRS UMS3033, Inserm US001, Bordeaux University. We thank A. Bezault for assistance with the Talos Arctica electron microscope. We thank J. Chicher and P. Hamman of the Strasbourg Esplanade proteomic analysis for the proteomic analysis.

This work was funded by a European Research Council Starting Grant (TransTryp ID:759120) and the IdEx junior excellence chair program of the Universite de Bordeaux to $\mathrm{YH}$ and the French National Program "Investissement d'Avenir" (Labex MitoCross), administered by the "Agence National de la Recherche", and referenced [ANR-11-LABX-0057_MITOCROSS] to MS. This project was supported by "Institut National de la Santé et de la Recherche Médicale" (INSERM), "Centre National de la Recherche Scientifique" (CNRS) and Université de Bordeaux.

\section{AUTHOR CONTRIBUTIONS}

$\mathrm{YH}, \mathrm{HS}$ and FW designed and coordinated the experiments. CP and SD purified kinetoplastids mitochondria. FW purified mitoribosomal complexes. LK performed the mass-spectrometry experiments. HS acquired the cryo-EM data and processed the cryo-EM results with $\mathrm{YH}$ and FW. HS, $\mathrm{YH}, \mathrm{FW}$ and $\mathrm{AB}$ built the atomic models. FW, HS, MS and $\mathrm{YH}$ interpreted the structures. FW, HS, CP, $\mathrm{YH}$ and $\mathrm{MS}$ wrote and edited the manuscript. $\mathrm{YH}$ directed the research.

\section{COMPETING FINANCIAL INTERESTS}

The authors declare no competing financial interests.

\section{DATA AVAILABILITY}

The cryo-EM maps of the mitoribosome have been deposited at the Electron Microscopy Data Bank (EMDB) with accession codes XXXX. Corresponding atomic models have been deposited in the Protein Data Bank (PDB) with PDB codes XXXX. The mass spectrometry proteomics data have been deposited to the ProteomeXchange Consortium via the PRIDE partner repository with the dataset identifier PXD018981. 
bioRxiv preprint doi: https://doi.org/10.1101/2020.05.02.073890; this version posted June 30,2020 . The copyright holder for this preprint (which was not certified by peer review) is the author/funder, who has granted bioRxiv a license to display the preprint in perpetuity. It is made available under aCC-BY-NC-ND 4.0 International license.

\section{ONLINE METHODS}

\section{Purification of $T$. cruzi and $L$. tarentolae mitochondria}

For mitochondria purification, protocols adapted from Hauser et al. $1996^{42}$ and Schneider et al. $2007^{43}$ were used. Quickly, cells were re-suspended in SoTE buffer $(600 \mathrm{mM}$ sorbitol, $20 \mathrm{mM}$ Tris- $\mathrm{HCl} \mathrm{pH} 7.5$, $1 \mathrm{mM}$ EDTA) to a final concentration of $2.5 \times 10^{9} \mathrm{cell} / \mathrm{s} / \mathrm{ml}$ and lysed by nitrogen cavitation at 80 bar for 1 hour. After pressure release the lysate was centrifuged and resuspended in SoTM buffer $(600 \mathrm{mM}$ sorbitol, $20 \mathrm{mM}$ Tris- $\mathrm{HCl} \mathrm{pH} \mathrm{7.5,5} \mathrm{mM} \mathrm{MgCl}$ ) for DNase I treatment during 15 minutes. EDTA was added to stop DNAse treatment and the sample was centrifuged, resuspended in 2 volumes of SoTE containing 50\% Histodenz ${ }^{\mathrm{TM}}$ (Sigma Aldrich D2158). For L. tarentolae the fraction was loaded onto a $21.7 \% / 25 \% / 28.3 / 31.6 \%$ Histodenz $^{\mathrm{TM}}$ step gradients. Gradients were centrifuged for 45 minutes at $100,000 \mathrm{~g}$ and the mitochondrial fraction was collected at the $25 \% / 28.3 \%$ interface. For $T$. brucei the fraction was loaded onto a $18 \% / 21 \% / 25 \% / 28 \%$ Histodenz $^{\mathrm{TM}}$ step gradient and the mitochondrial fraction was collected at the $21 \% / 25 \%$ interface.

\section{Purification of mitochondrial ribosomes}

For mitoribosome purification, protocols adapted from Waltz \& Soufari et al. ${ }^{10}$ were applied. Quickly, mitochondria were re-suspended in Lysis buffer $(20 \mathrm{mM}$ HEPES-KOH, pH 7.6, $100 \mathrm{mM} \mathrm{KCl}, 20 \mathrm{mM}$ $\mathrm{MgCl}_{2}, 1 \mathrm{mM}$ DTT, $1 \%$ Triton X-100, $2 \%$ DDM, supplemented with proteases inhibitors (Complete EDTA-free) to a concentration of $1 \mathrm{mg} / \mathrm{mL}$ and incubated for $15 \mathrm{~min}$ in $4^{\circ} \mathrm{C}$. Lysate was clarified by centrifugation at $30.000 \mathrm{~g}, 20 \mathrm{~min}$ at $4^{\circ} \mathrm{C}$. The supernatant was loaded on a $40 \%$ sucrose cushion in Monosome buffer (same as lysis buffer without Triton X-100 and with $0.02 \%$ DDM) and centrifuged at $235.000 \mathrm{~g}, 3 \mathrm{~h}, 4^{\circ} \mathrm{C}$. The crude ribosomes pellet was re-suspended in Monosome buffer and loaded on a $10-30 \%$ sucrose gradient in the same buffer and run for $16 \mathrm{~h}$ at $65,000 \mathrm{~g}$. Fractions corresponding to mitoribosomes were collected, pelleted and re-suspended in Monosome buffer.

\section{Grid preparation}

$4 \mu \mathrm{L}$ of the samples at a concentration of $2 \mu \mathrm{g} / \mu \mathrm{l}$ was applied onto Quantifoil R2/2 300-mesh holey carbon grid, which had been coated with thin home-made continuous carbon film and glow-discharged. The sample was incubated on the grid for $30 \mathrm{sec}$ and then blotted with filter paper for $2 \mathrm{sec}$ in a temperature and humidity controlled Vitrobot Mark IV $\left(T=4^{\circ} \mathrm{C}\right.$, humidity $100 \%$, blot force 5$)$ followed by vitrification in liquid ethane pre-cooled by liquid nitrogen.

\section{Single particle cryo-electron microscopy data collection}

For the two data-sets (Full and dissociated complexes), data collection was performed on a Talos Arctica instrument (Thermofisher) at $200 \mathrm{kV}$ using the EPU software (Thermofisher) for automated data acquisition. Data were collected at a nominal underfocus of -0.5 to $-2.7 \mu \mathrm{m}$ at a magnification of 120,000 $\mathrm{X}$ yielding a pixel size of $1.24 \AA$. Micrographs were recorded as movie stack on a Falcon III direct electron detector (Thermofisher), each movie stack were fractionated into 20 frames for a total exposure of $1 \mathrm{sec}$ corresponding to an electron dose of $60 \mathrm{e} / \AA \AA 2$.

\section{Electron microscopy image processing}

Drift and gain correction and dose weighting were performed using MotionCor2 ${ }^{44}$. A dose weighted average image of the whole stack was used to determine the contrast transfer function with the software Gctf ${ }^{45}$. The following process has been achieved using RELION 3.046. Particles were picked using a Laplacian of gaussian function (min diameter $280 \AA$, max diameter $480 \AA$ ). L. tarentolae full mitoribosome, after 2D classification, 303,140 particles were extracted with a box size of 400 pixels and binned four fold for 3D classification into six classes. Three classes depicting high-resolution features, consisting of 82,060 particles, were selected for refinement, yielding $3.9 \AA$ resolution. After focused refinement with a mask on the LSU, the body and the head of the SSU, 3.6, 4 and $3.8 \AA$ A resolution were respectively obtained. For the assembly intermediate of the LSU, after 2D classification, 215,120 particles were extracted with a box size of 400 pixels and binned three fold for 3D classification into 8 classes. Two classes, consisting of 59,200 particles, depicting high-resolution features were selected for refinement, yielding $3.4 \AA$ resolution.

For the T. cruzi full mitoribosomes reconstruction, 126,340 particles were selected after 3D classification for refinement, resulting in a $6 \AA$ resolution reconstruction, which was further refine to $3.7 \AA$ and $4.5 \AA$ resolution for the LSU and SSU respectively. For the T. cruzi mt-IF3 SSU complex, 148,180 particles were selected after 3D classification for refinement, resulting in a $3.5 \AA$ resolution reconstruction, which was further refine to $3.1 \AA$ and $3.2 \AA$ resolution for the SSU body and SSU head respectively. Determination of the local resolution of the final density map was performed using ResMap ${ }^{40}$. 
bioRxiv preprint doi: https://doi.org/10.1101/2020.05.02.073890; this version posted June 30, 2020. The copyright holder for this preprint (which was not certified by peer review) is the author/funder, who has granted bioRxiv a license to display the preprint in perpetuity. It is made available under aCC-BY-NC-ND 4.0 International license.

\section{Structure building and model refinement}

The atomic models of the kinetoplastid mitoribosomes were built into the high-resolution maps using Coot, Phoenix and Chimera. Atomic models from E. coli ribosome $(5 \mathrm{kcr})^{47}$, and trypanosoma mitoribosome $(6 \mathrm{hiv})^{3}$ were used as starting points for protein identification and modelisation. For the Leishmania mitoribosome, atomic models were build using $L$. major protein sequences due to the poor quality of $L$. tarentolae available data. The online SWISS-MODEL service was used to generate initial models for bacterial and mitochondria conserved r-proteins. Models were then rigid body fitted to the density in Chimera ${ }^{48}$ and all subsequent modeling was done in $\mathrm{Coot}^{49}$. For the LSU ribosomal RNA, the 23S rRNA from E.coli was docked into the maps and used as template from positioning and reconstruction. Punctual differences were done in Chimera using the "swapna" command line and the model was then further refined in Coot. The global atomic model was refined with VMD using the Molecular Dynamic Flexible Fitting (MDFF) then with PHENIX using a combination of real and reciprocal space refinement for proteins.

\section{Proteomic and statistical analyses of mitochondrial ribosome composition}

Mass spectrometry analyses of the ribosome fractions were performed at the Strasbourg-Esplanade proteomic platform and performed as previously ${ }^{10,50}$. In brief, proteins were trypsin digested and mass spectrometry analyses were carried out by nano LC-ESI-MS/MS analysis on a Thermo QExactive+ mass spectrometer. Quantitative label-free proteomics analysis was performed through in-house bioinformatics pipelines.

\section{Figure preparation}

Figures featuring cryo-EM densities as well as atomic models were visualized with UCSF ChimeraX ${ }^{51}$ and Chimera ${ }^{48}$. 
bioRxiv preprint doi: https://doi.org/10.1101/2020.05.02.073890; this version posted June 30,2020 . The copyright holder for this preprint

\section{References}

1. Stuart, K. et al. Kinetoplastids: related protozoan pathogens, different diseases. J. Clin. Invest. 118, 1301-1310 (2008).

2. Simpson, L., Thiemann, O. H., Savill, N. J., Alfonzo, J. D. \& Maslov, D. A. Evolution of RNA editing in trypanosome mitochondria. Proc. Natl. Acad. Sci. 97, 6986-6993 (2000).

3. Ramrath, D. J. F. et al. Evolutionary shift toward protein-based architecture in trypanosomal mitochondrial ribosomes. Science. 362, eaau7735 (2018).

4. Waltz, F. \& Giegé, P. Striking Diversity of Mitochondria-Specific Translation Processes across Eukaryotes. Trends Biochem. Sci. 45, 149-162 (2019).

5. Bieri, P., Greber, B. J. \& Ban, N. High-resolution structures of mitochondrial ribosomes and their functional implications. Curr. Opin. Struct. Biol. 49, 44-53 (2018).

6. Saurer, M. et al. Mitoribosomal small subunit biogenesis in trypanosomes involves an extensive assembly machinery. Science. 365, 1144-1149 (2019).

7. Jackson, A. P. et al. Kinetoplastid Phylogenomics Reveals the Evolutionary Innovations Associated with the Origins of Parasitism. Curr. Biol. 26, 161-172 (2016).

8. Desai, N., Brown, A., Amunts, A. \& Ramakrishnan, V. The structure of the yeast mitochondrial ribosome. Science (80-. ). 355, 528-531 (2017).

9. Amunts, A., Brown, A., Toots, J., Scheres, S. H. W. \& Ramakrishnan, V. The structure of the human mitochondrial ribosome. Science. 348, 95-98 (2015).

10. Waltz, F., Soufari, H., Bochler, A., Giegé, P. \& Hashem, Y. Cryo-EM structure of the RNA-rich plant mitochondrial ribosome. Nat. Plants 6, 377-383 (2020).

11. Kummer, E. et al. Unique features of mammalian mitochondrial translation initiation revealed by cryo-EM. Nature 560, 263-267 (2018).

12. Mallam, A. L., Sidote, D. J. \& Lambowitz, A. M. Molecular insights into RNA and DNA helicase evolution from the determinants of specificity for a DEAD-box RNA helicase. Elife 3, e04630 (2014).

13. Zeng, R., Smith, E. \& Barrientos, A. Yeast Mitoribosome Large Subunit Assembly Proceeds by Hierarchical Incorporation of Protein Clusters and Modules on the Inner Membrane. Cell Metab. 27, 645-656.e7 (2018).

14. Zhou, D. et al. Cryo-EM structure of an early precursor of large ribosomal subunit reveals a halfassembled intermediate. Protein Cell 10, 120-130 (2019).

15. Zhang, X. et al. Structural insights into the function of a unique tandem GTPase EngA in bacterial ribosome assembly. Nucleic Acids Res. 42, 13430-13439 (2014).

16. Seffouh, A. et al. Structural consequences of the interaction of RbgA with a 50S ribosomal subunit assembly intermediate. Nucleic Acids Res. 47, 10414-10425 (2019).

17. Wittinghofer, A. \& Vetter, I. R. Structure-Function Relationships of the G Domain, a Canonical Switch Motif. Annu. Rev. Biochem. 80, 943-971 (2011).

18. Pausch, P. et al. Structural basis for (p)ppGpp-mediated inhibition of the GTPase RbgA. J. Biol. Chem. 293, 19699-19709 (2018).

19. Sivaraman, J., lannuzzi, P., Cygler, M. \& Matte, A. Crystal Structure of the RluD Pseudouridine Synthase Catalytic Module, an Enzyme that Modifies 23S rRNA and is Essential for Normal Cell Growth of Escherichia coli. J. Mol. Biol. 335, 87-101 (2004).

20. Vaidyanathan, P. P., Deutscher, M. P. \& Malhotra, A. RluD, a highly conserved pseudouridine synthase, modifies $50 S$ subunits more specifically and efficiently than free $23 S$ rRNA. RNA 13, 1868-1876 (2007).

21. Yang, H. et al. Crystal structure of the nosiheptide-resistance methyltransferase of streptomyces actuosus. Biochemistry 49, 6440-6450 (2010).

22. Mosbacher, T. G., Bechthold, A. \& Schulz, G. E. Structure and Function of the Antibiotic Resistance-mediating Methyltransferase AviRb from Streptomyces viridochromogenes. J. Mol. Biol. 345, 535-545 (2005).

23. Brown, A. et al. Structures of the human mitochondrial ribosome in native states of assembly. Nat. Struct. Mol. Biol. 24, 866-869 (2017).

24. $\mathrm{Li}, \mathrm{X}$. et al. Structure of Ribosomal Silencing Factor Bound to Mycobacterium tuberculosis Ribosome. Structure 23, 1858-1865 (2015).

25. Khusainov, I. et al. Mechanism of ribosome shutdown by RsfS in Staphylococcus aureus revealed by integrative structural biology approach. Nat. Commun. 11, 1656 (2020).

26. Waltz, F. \& Giegé, P. Striking Diversity of Mitochondria-Specific Translation Processes across Eukaryotes. Trends Biochem. Sci. 45, 149-162 (2020).

27. Melnikov, S. et al. One core, two shells: bacterial and eukaryotic ribosomes. Nat. Struct. Mol. 
bioRxiv preprint doi: https://doi.org/10.1101/2020.05.02.073890; this version posted June 30,2020 . The copyright holder for this preprint (which was not certified by peer review) is the author/funder, who has granted bioRxiv a license to display the preprint in perpetuity. It is made available under aCC-BY-NC-ND 4.0 International license.

Biol. 19, 560-7 (2012).

28. Greber, B. J. et al. Insertion of the Biogenesis Factor Rei1 Probes the Ribosomal Tunnel during 60S Maturation. Cell 164, 91-102 (2016).

29. Del Campo, M., Ofengand, J. \& Malhotra, A. Crystal structure of the catalytic domain of RluD, the only rRNA pseudouridine synthase required for normal growth of Escherichia coli. RNA 10, 231-239 (2004).

30. Rebelo-Guiomar, P., Powell, C. A., Van Haute, L. \& Minczuk, M. The mammalian mitochondrial epitranscriptome. Biochimica et Biophysica Acta - Gene Regulatory Mechanisms 1862, 429-446 (2019).

31. Polikanov, Y. S., Melnikov, S. V., Söll, D. \& Steitz, T. A. Structural insights into the role of rRNA modifications in protein synthesis and ribosome assembly. Nat. Struct. Mol. Biol. 22, 342-344 (2015).

32. Parey, K. et al. High-resolution cryo-EM structures of respiratory complex I: Mechanism, assembly, and disease. Sci. Adv. 5, eaax9484 (2019).

33. Agip, A.-N. A. et al. Cryo-EM structures of complex I from mouse heart mitochondria in two biochemically defined states. Nat. Struct. Mol. Biol. 25, 548-556 (2018).

34. Soufari, H., Parrot, C., Kuhn, L., Waltz, F. \& Hashem, Y. Specific features and assembly of the plant mitochondrial complex I revealed by cryo-EM. bioRxiv 13, (2020).

35. Baradaran, R., Berrisford, J. M., Minhas, G. S. \& Sazanov, L. A. Crystal structure of the entire respiratory complex I. Nature 494, 443-448 (2013).

36. Gray, M. W. Mitochondrial Evolution. Cold Spring Harb. Perspect. Biol. 4, a011403-a011403 (2012).

37. Sazanov, L. A. A giant molecular proton pump: structure and mechanism of respiratory complex I. Nat. Rev. Mol. Cell Biol. 16, 375-388 (2015).

38. Valach, M., Léveillé-Kunst, A., Gray, M. W. \& Burger, G. Respiratory chain Complex I of unparalleled divergence in diplonemids. J. Biol. Chem. 293, 16043-16056 (2018).

39. Jakob, M. et al. Mitochondrial growth during the cell cycle of Trypanosoma brucei bloodstream forms. Sci. Rep. 6, 36565 (2016).

40. Kucukelbir, A., Sigworth, F. J. \& Tagare, H. D. Quantifying the local resolution of cryo-EM density maps. Nat. Methods 11, 63-65 (2014).

41. Yang, $\mathrm{H}$. et al. Crystal Structure of the Nosiheptide-Resistance Methyltransferase of Streptomyces actuosus. Biochemistry 49, 6440-6450 (2010).

42. Hauser, R., Pypaert, M., Häusler, T., Horn, E. K. \& Schneider, A. In vitro import of proteins into mitochondria of Trypanosoma brucei and Leishmania tarentolae. J. Cell Sci. 109, 517-523 (1996).

43. Schneider, A., Bouzaidi-Tiali, N., Chanez, A.-L. \& Bulliard, L. ATP Production in Isolated Mitochondria of Procyclic Trypanosoma brucei. in Methods in molecular biology (Clifton, N.J.) 372, 379-387 (2007).

44. Zheng, S. Q. et al. MotionCor2: anisotropic correction of beam-induced motion for improved cryoelectron microscopy. Nat. Methods 14, 331-332 (2017).

45. Zhang, K. Gctf: Real-time CTF determination and correction. J. Struct. Biol. 193, 1-12 (2016).

46. Zivanov, J. et al. New tools for automated high-resolution cryo-EM structure determination in RELION-3. Elife 7, (2018).

47. Arenz, S. et al. Structures of the orthosomycin antibiotics avilamycin and evernimicin in complex with the bacterial 70 S ribosome. Proc. Natl. Acad. Sci. 113, 7527-7532 (2016).

48. Pettersen, E. F. et al. UCSF Chimera--a visualization system for exploratory research and analysis. J. Comput. Chem. 25, 1605-12 (2004).

49. Emsley, P., Lohkamp, B., Scott, W. G. \& Cowtan, K. Features and development of Coot. Acta Crystallogr. Sect. D Biol. Crystallogr. 66, 486-501 (2010).

50. Waltz, F. et al. Small is big in Arabidopsis mitochondrial ribosome. Nat. Plants 5, 106-117 (2019).

51. Goddard, T. D. et al. UCSF ChimeraX: Meeting modern challenges in visualization and analysis. Protein Sci. 27, 14-25 (2018). 
bioRxiv preprint doi: https://doi.org/10.1101/2020.05.02.073890; this version posted June 30, 2020. The copyright holder for this preprint (which was not certified by peer review) is the author/funder, who has granted bioRxiv a license to display the preprint in perpetuity. It is

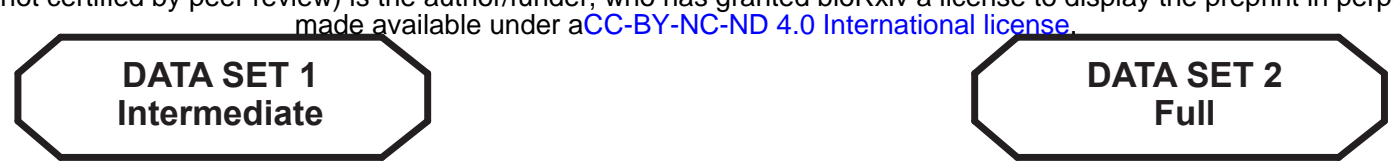

a

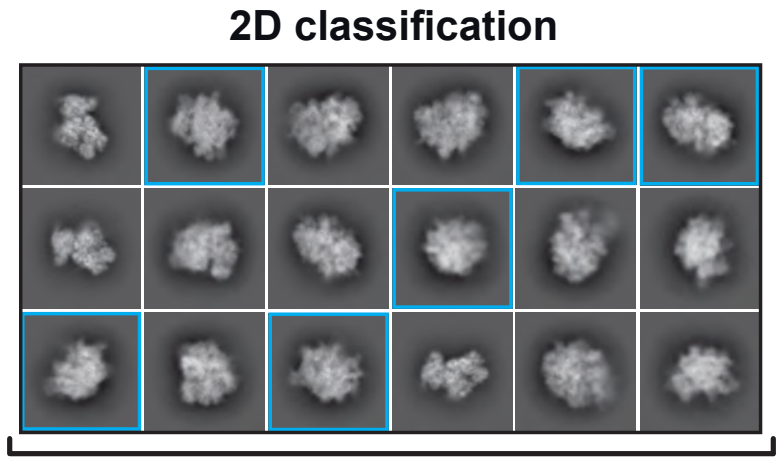

215,120 particles

b

3D classification
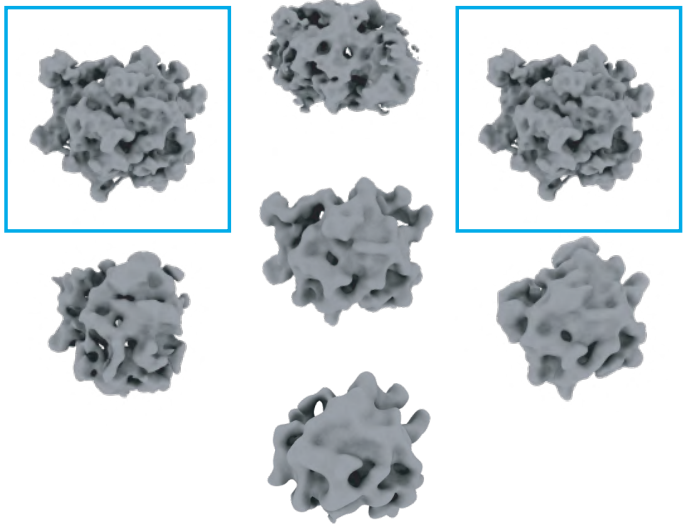

59,200 particles

\section{D refinement}

LSU assembly intermediate

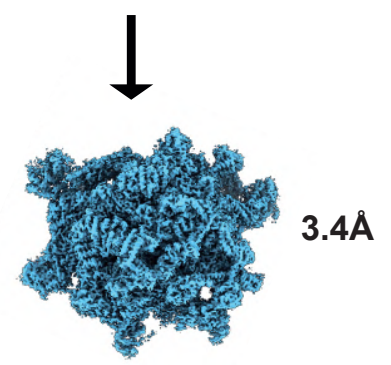

2D classification

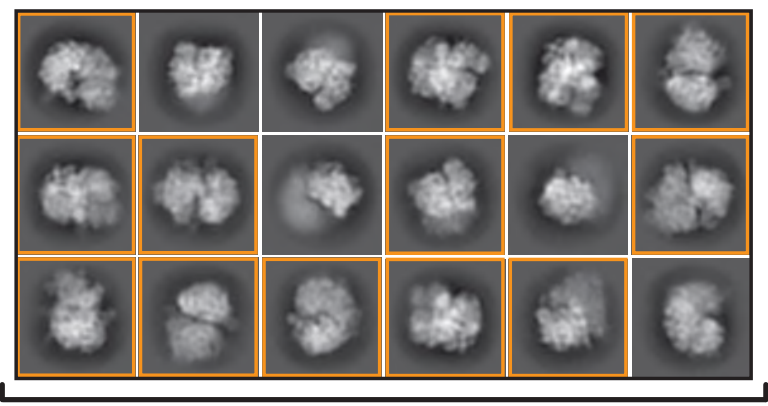

303,140 particles

\section{D classification}
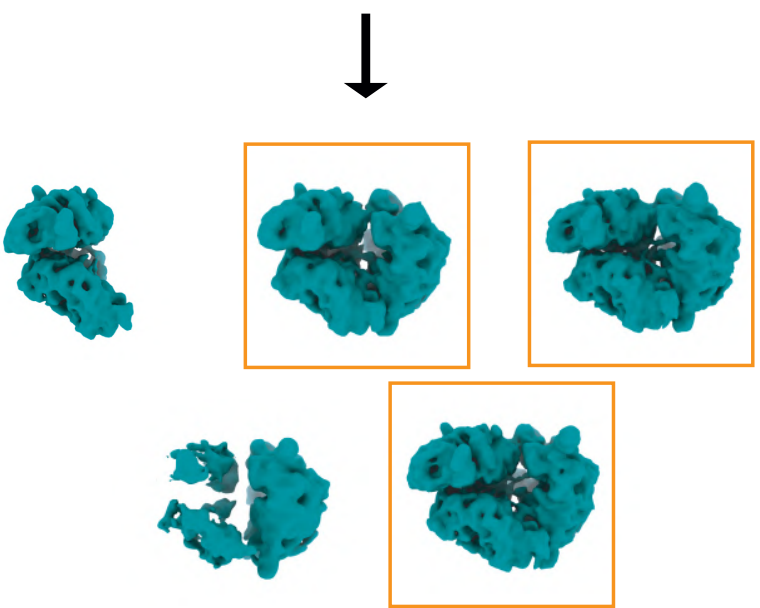

82,060 particles

$3 D$ refinement

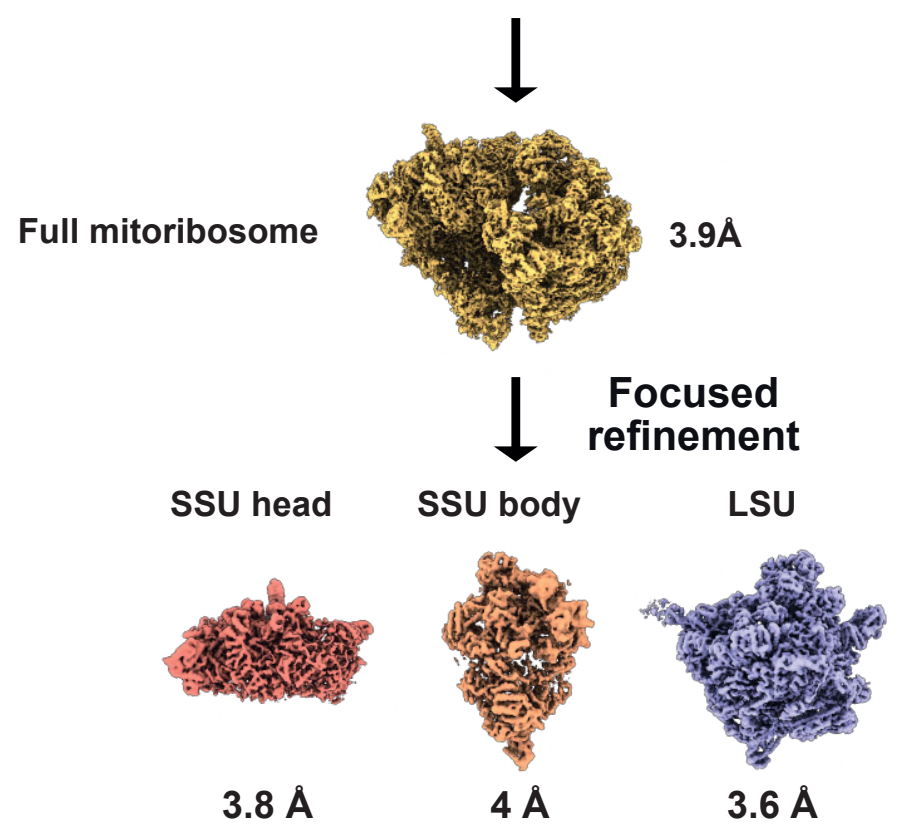

Extended Data Figure 1. Data processing workflow of $L$. tarentolae data sets

Graphical summary of the processing workflow described in Methods for the $L$. tarentolae samples, resulting in the LSU assembly intermediate for Data set 1 and the full mitoribosome for Data set 2. 2D classes are presented in (a) and $3 \mathrm{D}$ processing and refinement presented in (b). 
bioRxiv preprint doi: https://doi.org/10.1101/2020.05.02.073890; this version posted June 30, 2020. The copyright holder for this preprint (which was not certified by peer review) is the author/funder, who has granted bioRxiv a license to display the preprint in perpetuity. It is made available under aCC-BY-NC-ND 4.0 Internationalljicense.
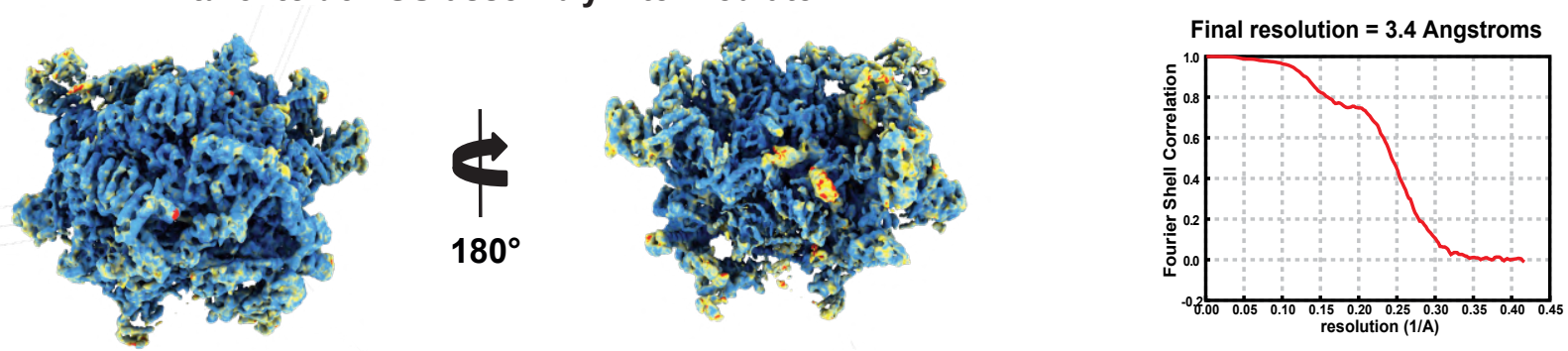

\section{L.tarentolae full ribosome}
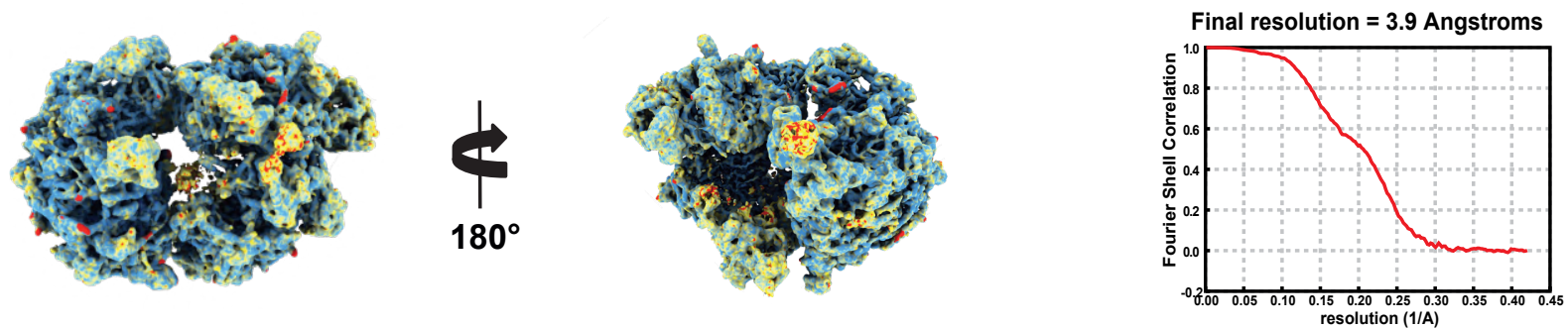

\section{L.tarentolae focused LSU}
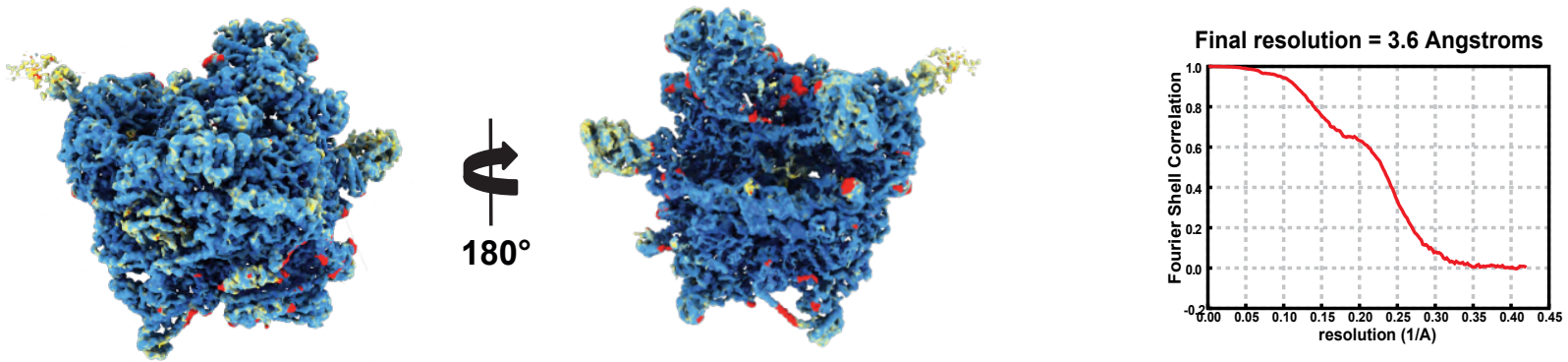

\section{L.tarentolae focused SSU body}
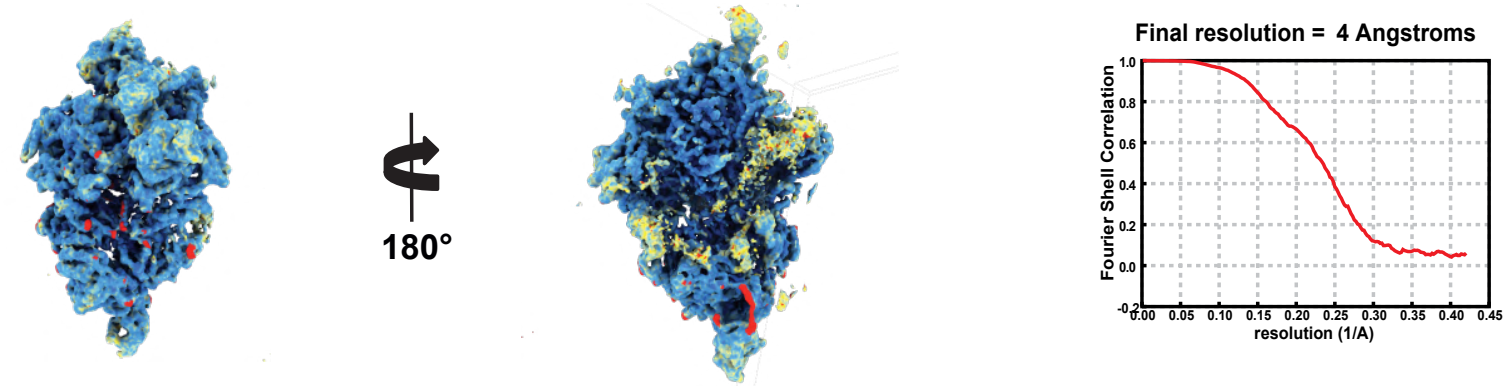

\section{L.tarentolae focused SSU head}
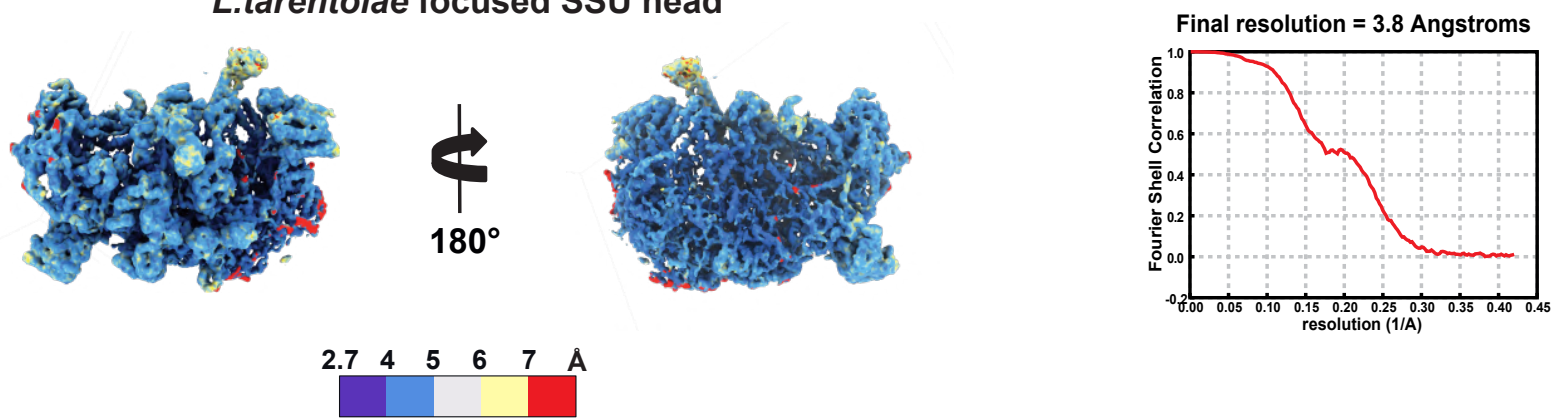

Extended Data Figure 2. Local resolution of L. tarentolae final reconstructions

Local resolutions of the different reconstructions are presented. The maps are colored by resolution, generated using $\operatorname{ResMap}^{40}(\mathbf{a})$. For both reconstructions FSC plots are displayed for resolution estimation (b). The map resolution is calculated at the 0.143 threshold. 
bioRxiv preprint doi: https://doi.org/10.1101/2020.05.02.073890; this version posted June 30, 2020. The copyright holder for this preprint (which was not certified by peer review) is the author/funder, who has granted bioRxiv a license to display the preprint in perpetuity. It is made available under aCC-BY-NC-ND 4.0 International license.

a

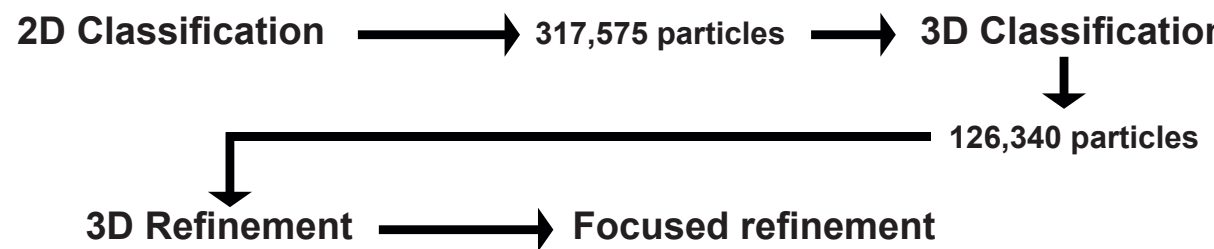

b
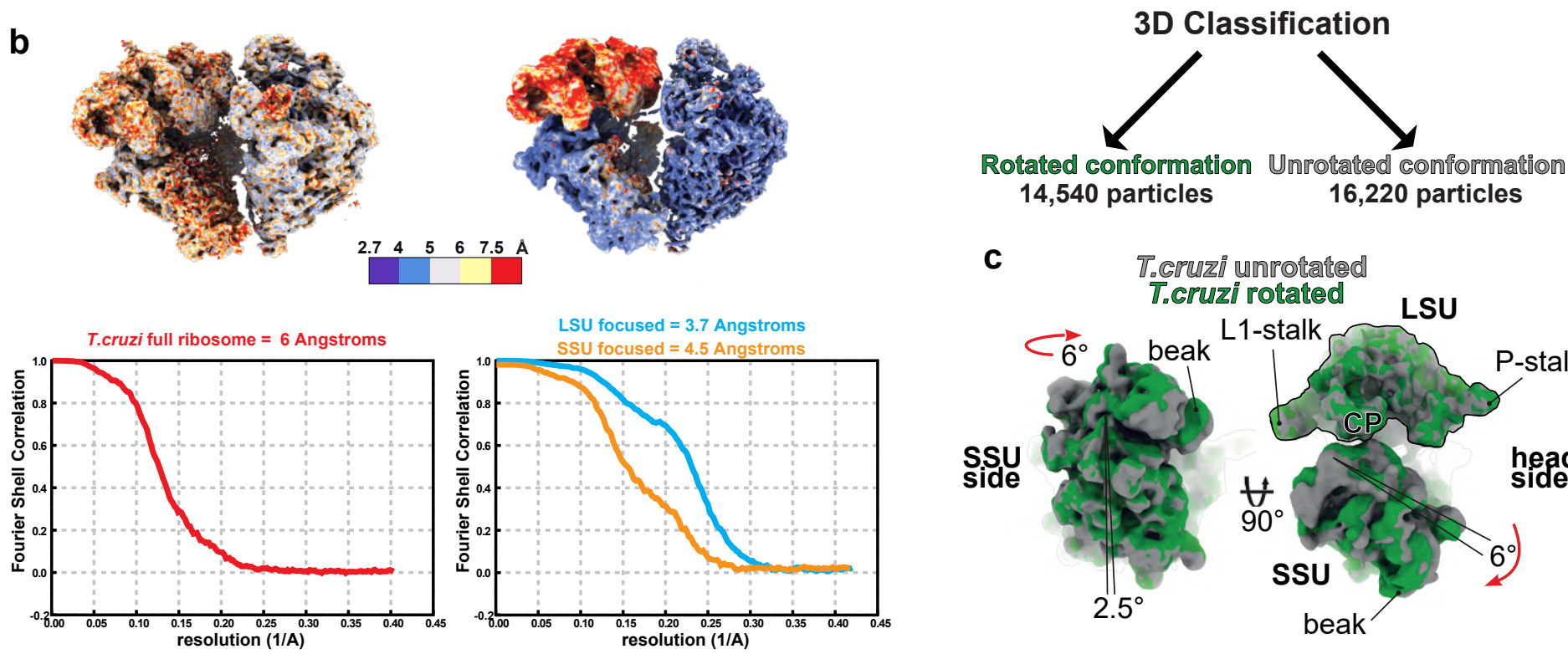

16,220 particles
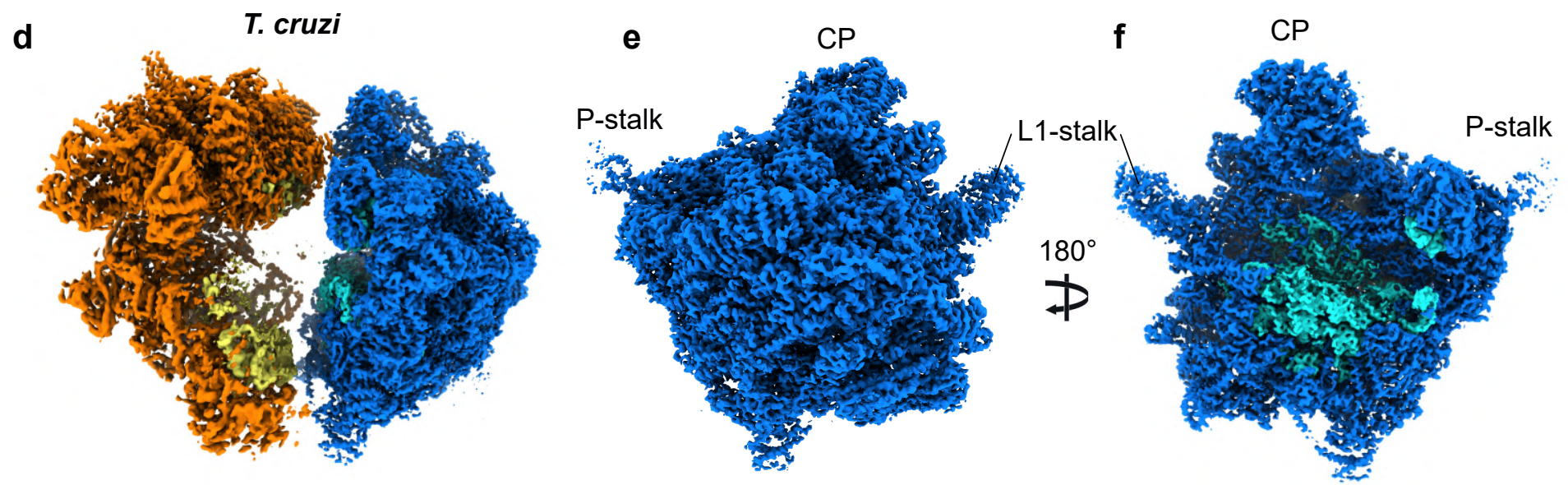

Extended Data Figure 3. Data processing and cryo-EM reconstructions of T. cruzi mitoribosome

Graphical summary of the processing workflow T. cruzi full mitoribosome. 2D classification and 3D processing are presented in (a) with respective ResMap ${ }^{40}$ representation and FSC plots presented in (b). Second round of 3D classification lead to the identification of two rotational states presented in (c). Cryo-EM reconstructions of $T$. cruzi full mitoribosome (d) as well as the mature LSU, seen from the solvent view (e) and the interface view (f). Compared with the L.tarentolae reconstructions presented in Figure 1, the ribosomes are nearly identical. 
bioRxiv preprint doi: https://doi.org/10.1101/2020.05.02.073890; this version posted June 30, 2020. The copyright holder for this preprint (which was not certified by peer review) is the author/funder, who has granted bioRxiv a license to display the preprint in perpetuity. It is

a head

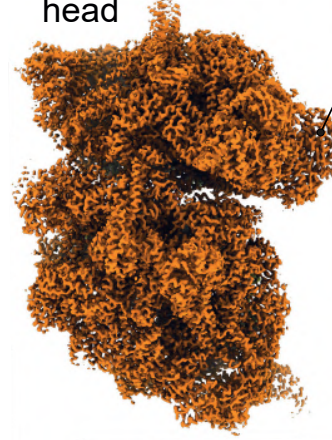

b

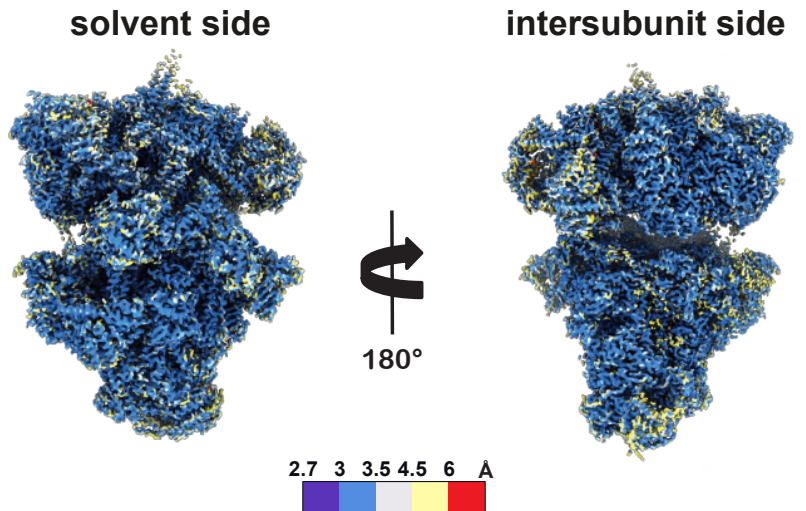

intersubunit side
C
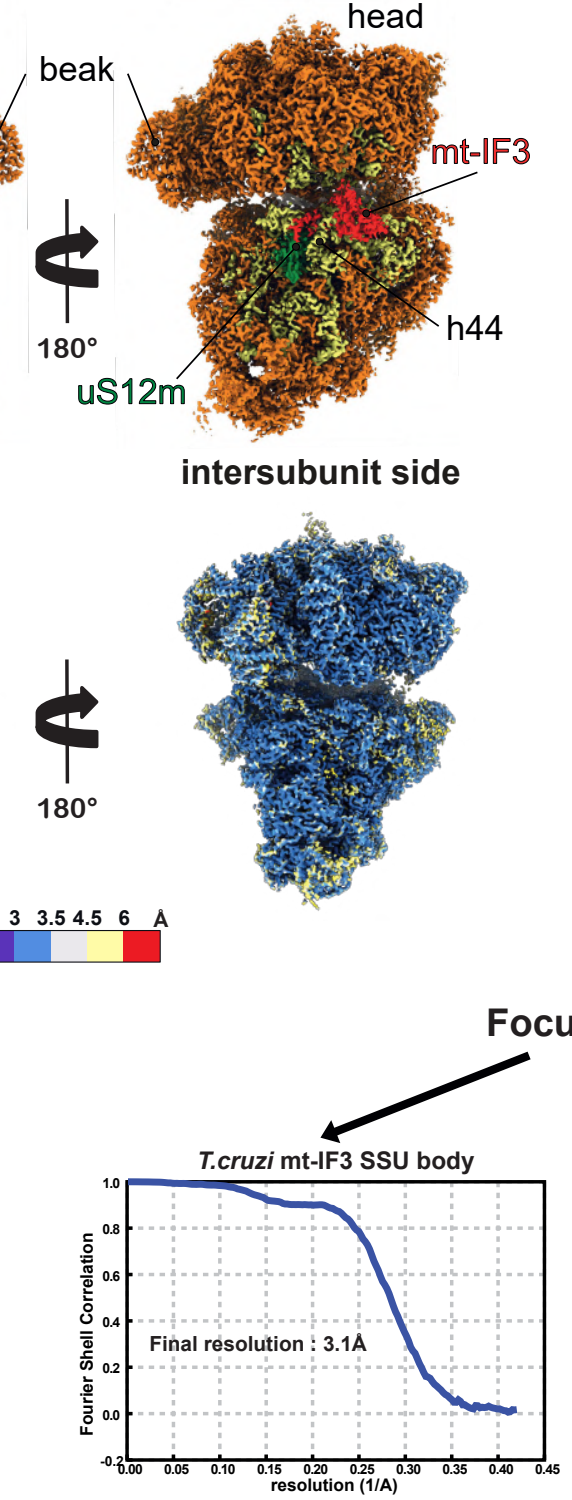

2D Classification<smiles>[CH]1[CH]C[CH]1</smiles>

422,120 particles

3D Classification

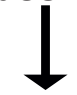

148,180 particles

3D Refinement
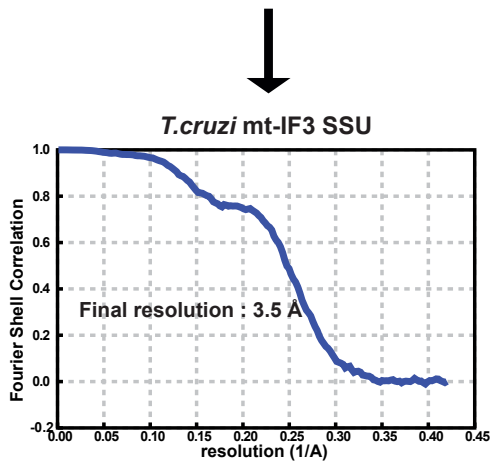

d

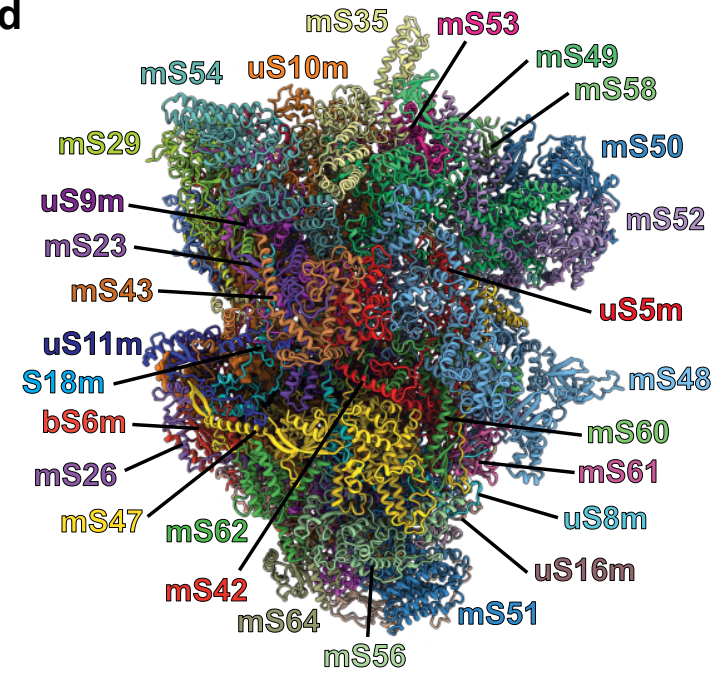

Solvent side

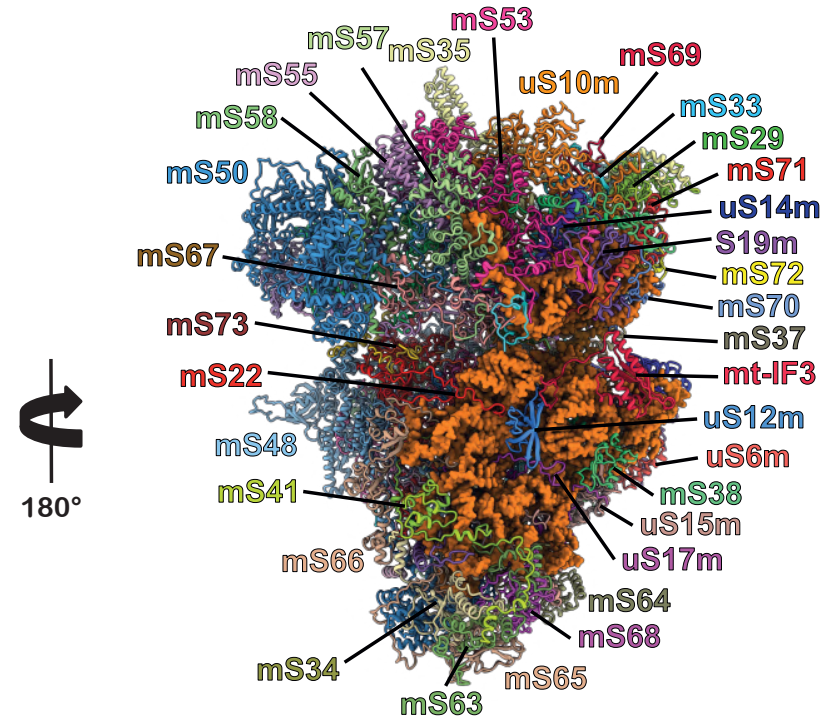

Intersubunit side

Extended Data Figure 4. Data processing and model of the mt-IF3 SSU of T. cruzi

Cryo-EM map reconstruction of the T. cruzi in presence of mt-IF3 is shown in (a), with r-proteins colored in orange, 9S rRNA in yellow, mt-IF3 in red and uS12m in green. Local resolution generated using ResMap ${ }^{40}$ are shown in (b), and the processing workflow with the respective FSC plots for initial and focused 3D refinement are displayed in (c). The resulting atomic model is presented in (d), each r-proteins are individually annotated, 9S rRNA is colored in orange. 
bioRxiv preprint doi: https://doi.org/10.1101/2020.05.02.073890; this version posted June 30, 2020. The copyright holder for this preprint (which was not certified by peer review) is the author/funder, who has granted bioRxiv a license to display the preprint in perpetuity. It is made available under aCC-BY-NC-ND 4.0 International license.

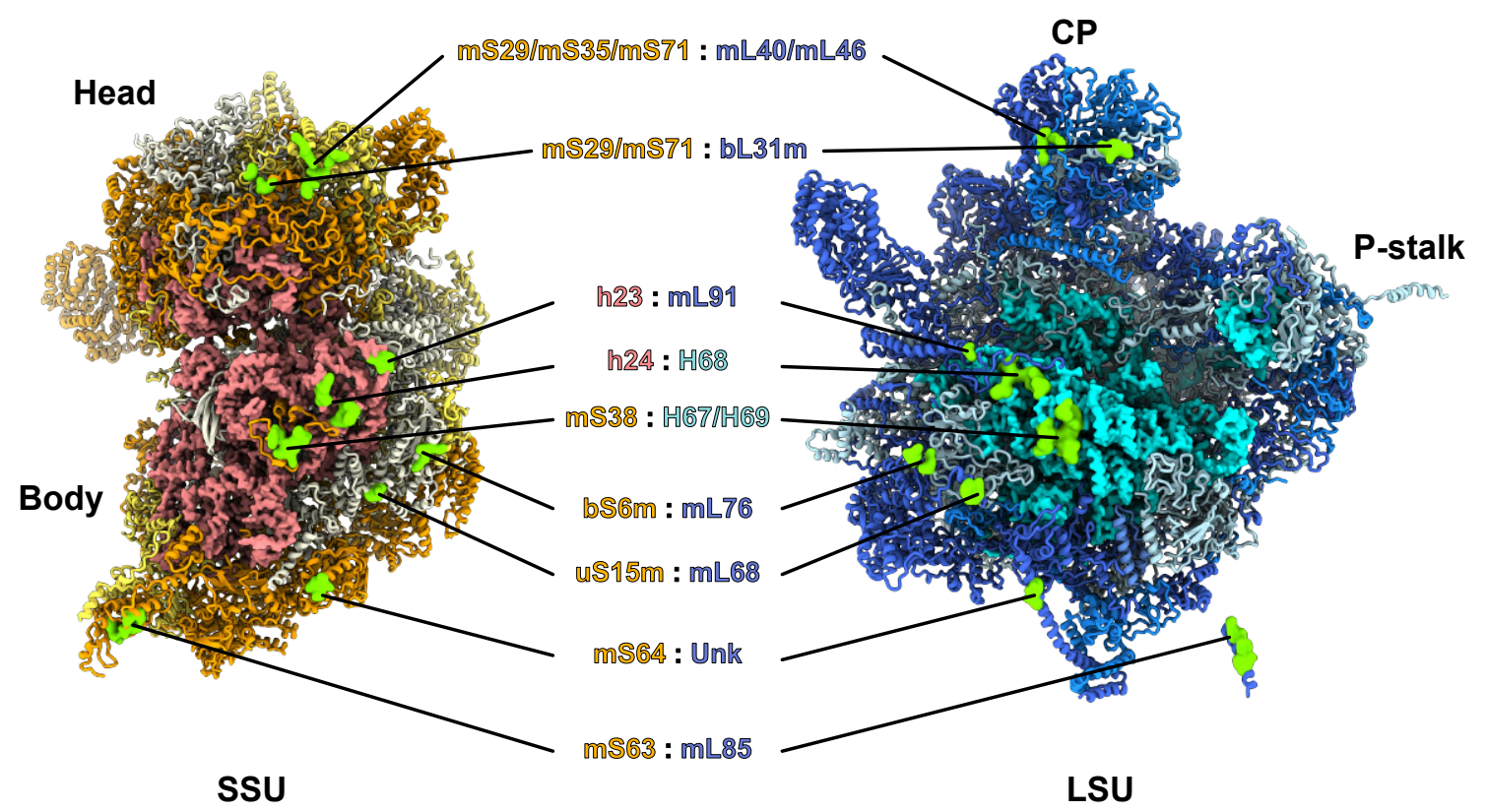

Extended Data Figure 5. Intersubunit bridges

List of the intersubunit bridges observed in the mature and full kinetoplastid mitoribosomes. Both the SSU and LSU are presented on the intersubunit side and bridge positions are indicated in green. Most of the bridges involve protein:protein interactions, except for the highly conserved rRNA:rRNA bridge between h24 and H68. Overall, the other bridge positions seem to be common with other mitoribosomes and bacterial ribosomes but involve mitochondria and kinetoplastid-specific r-proteins, for example, bL31m is the only bacterial-type r-protein involved in the bridges between the SSU's head and LSU's CP. One truly kinetoplastid-specific bridge is observed with mS63 and $\mathrm{mL} 85$, which involves kinetoplastid only r-proteins. 
bioRxiv preprint doi: https://doi.org/10.1101/2020.05.02.073890; this version posted June 30,2020 . The copyright holder for this preprint (which was not certified by peer review) is the author/funder, who has granted bioRxiv a license to display the preprint in perpetuity. It is made available under acepprotêtins. 0 International license.

Assembly intermediate
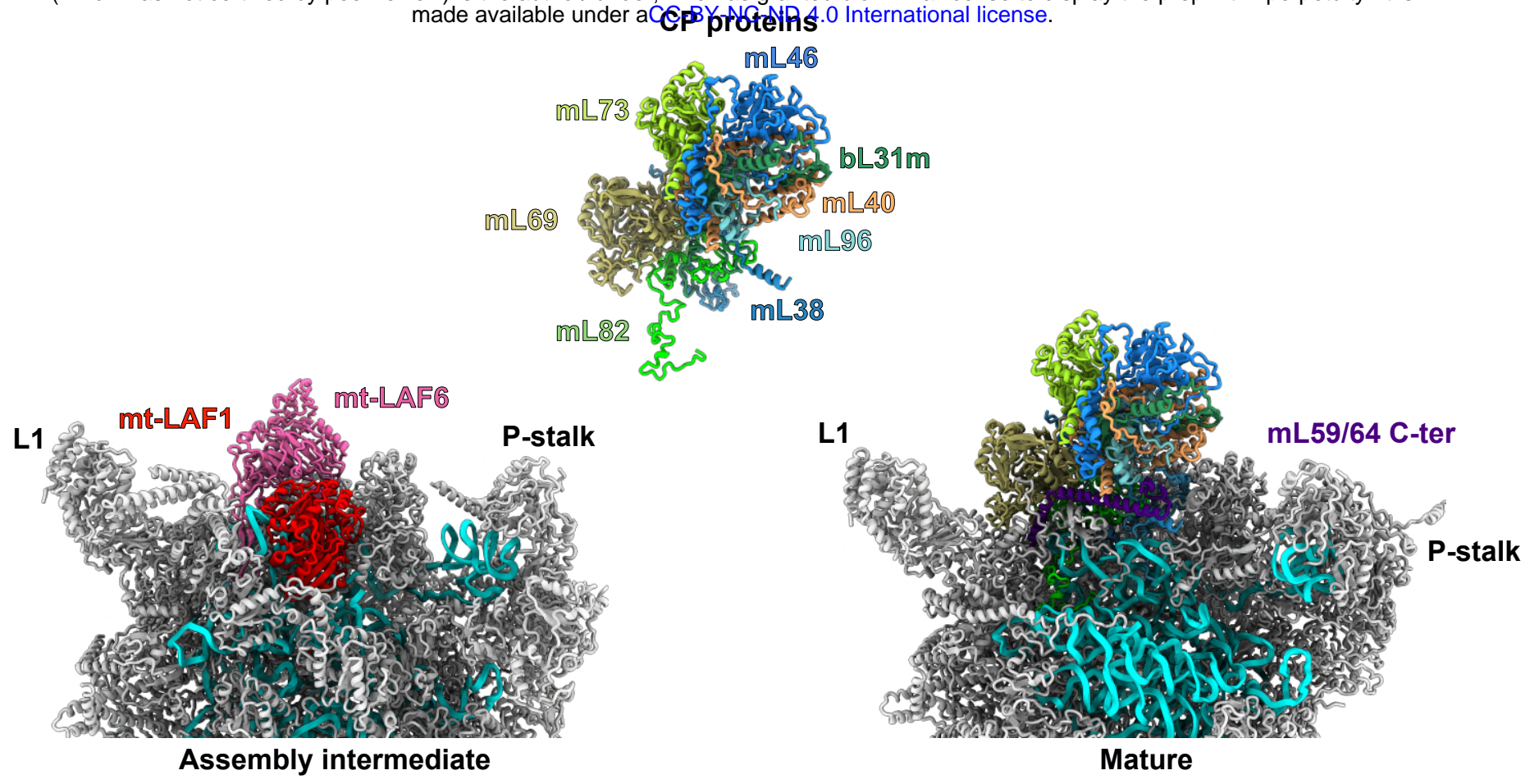

Extended Data Figure 6. Central protuberance maturation in Leishmania LSU

Comparison of the assembly intermediate and mature CP area of the LSU. In the assembly intermediate, CP proteins are prevented from binding by mt-LAF1 and mt-LAF6. Upon release of the maturation factors the whole CP block can dock the LSU and additional r-proteins contacting the CP, like bL33m and the C-terminus of mL59/64 can lock the structure. 12S rRNA is displayed in cyan. 
bioRxiv preprint doi: https://doi.org/10.1101/2020.05.02.073890; this version posted June 30, 2020. The copyright holder for this preprint (which was not certified by peer review) is the author/funder, who has granted bioRxiv a license to display the preprint in perpetuity. It is

a

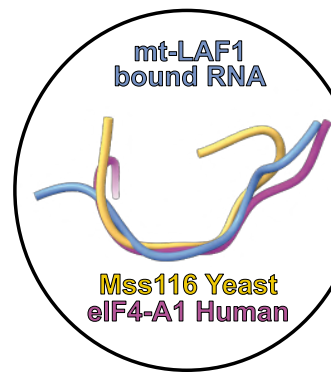

C

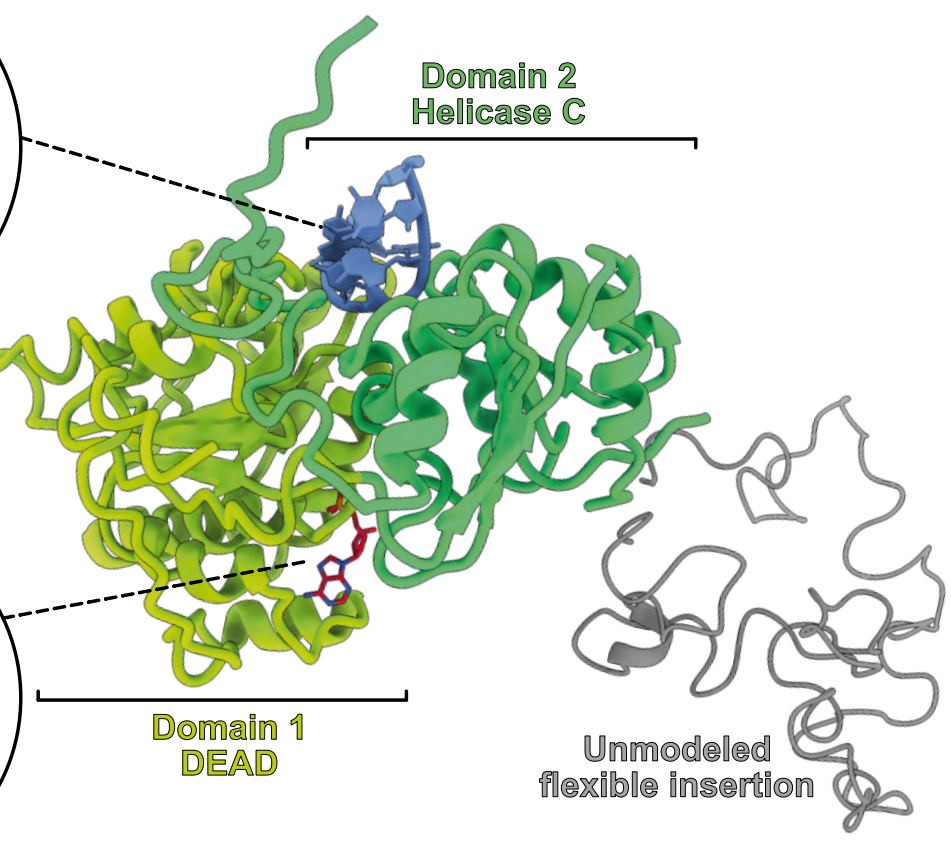

d

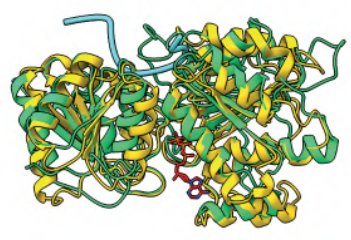

Mss116 Yeast (4TYWW)

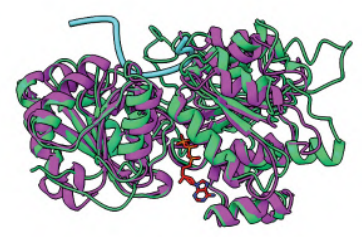

elf 4 -A1 Human (5ZC9)

e

\begin{tabular}{|c|c|c|c|}
\hline 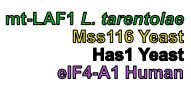 & $\begin{array}{r}86 \\
62 \\
1 \\
1\end{array}$ & 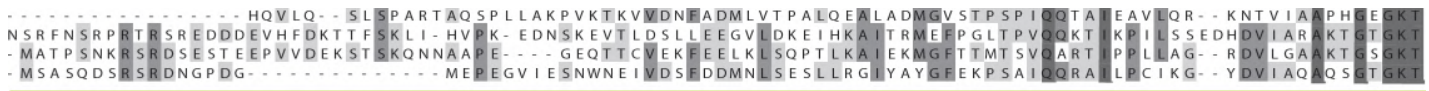 & $\begin{array}{l}16 \\
153 \\
93 \\
83\end{array}$ \\
\hline 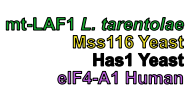 & $\begin{array}{r}165 \\
160 \\
94 \\
84\end{array}$ & 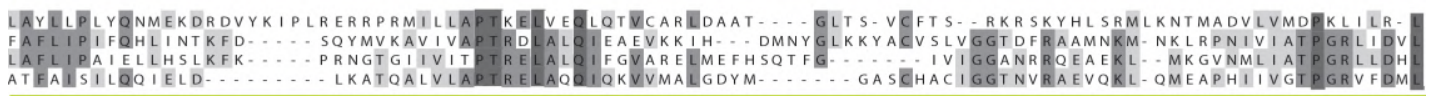 & $\begin{array}{l}25 \\
25 \\
17 \\
16\end{array}$ \\
\hline 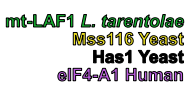 & $\begin{array}{l}257 \\
251 \\
180 \\
167\end{array}$ & 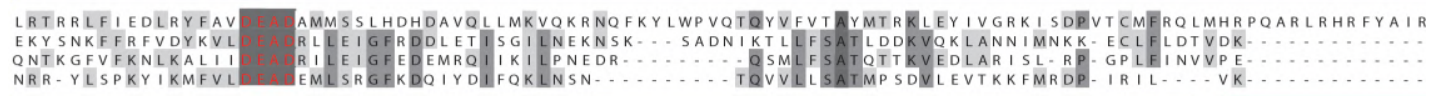 & 25 \\
\hline 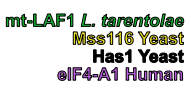 & $\begin{array}{l}357 \\
334 \\
256 \\
238\end{array}$ & 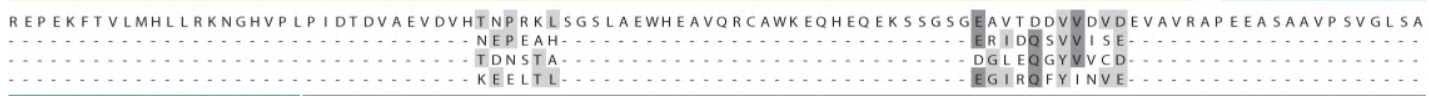 & $\begin{array}{l}27 \\
25\end{array}$ \\
\hline 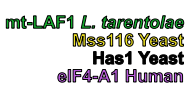 & $\begin{array}{l}457 \\
351 \\
273 \\
255\end{array}$ & 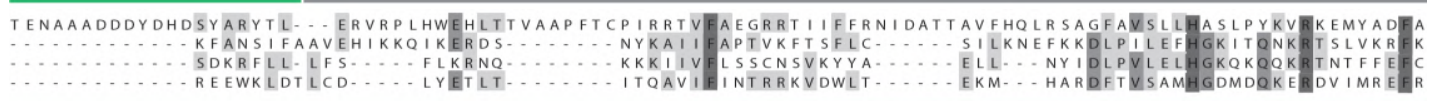 & $\begin{array}{l}55 \\
42 \\
33 \\
31\end{array}$ \\
\hline 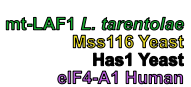 & $\begin{array}{l}554 \\
424 \\
337 \\
320\end{array}$ & 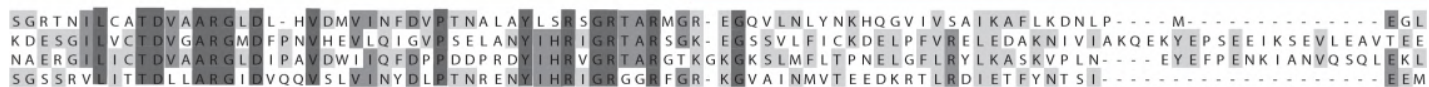 & $\begin{array}{l}63 \\
52 \\
43 \\
39\end{array}$ \\
\hline
\end{tabular}

Extended Data Figure 7. Structural conservation and sequence comparison of the DEAD-box RNA helicase mtLAF1

mt-LAF1 is shown in (c) with its DEAD and helicase domains colored in green and its unmodeled flexible insertion shown in grey. Aside the insertion, the helicase appears to be conserved with enzymes of the DEAD-box family, highlighted by the superimpositions (d) and sequence alignments (e) of mt-LAF1 with yeast mitochondrial Mss116 enzyme $^{1213}$, or cytosolic Has1 and elF4-A1. The enzyme is in closed state (d) and the interaction with RNA (a) as well as with the ATP ligand (b) is highly conserved. 
bioRxiv preprint doi: https://doi.org/10.1101/2020.05.02.073890; this version posted June 30, 2020. The copyright holder for this preprint (which was not certified by peer review) is the author/funder, who has granted bioRxiv a license to display the preprint in perpetuity. It is
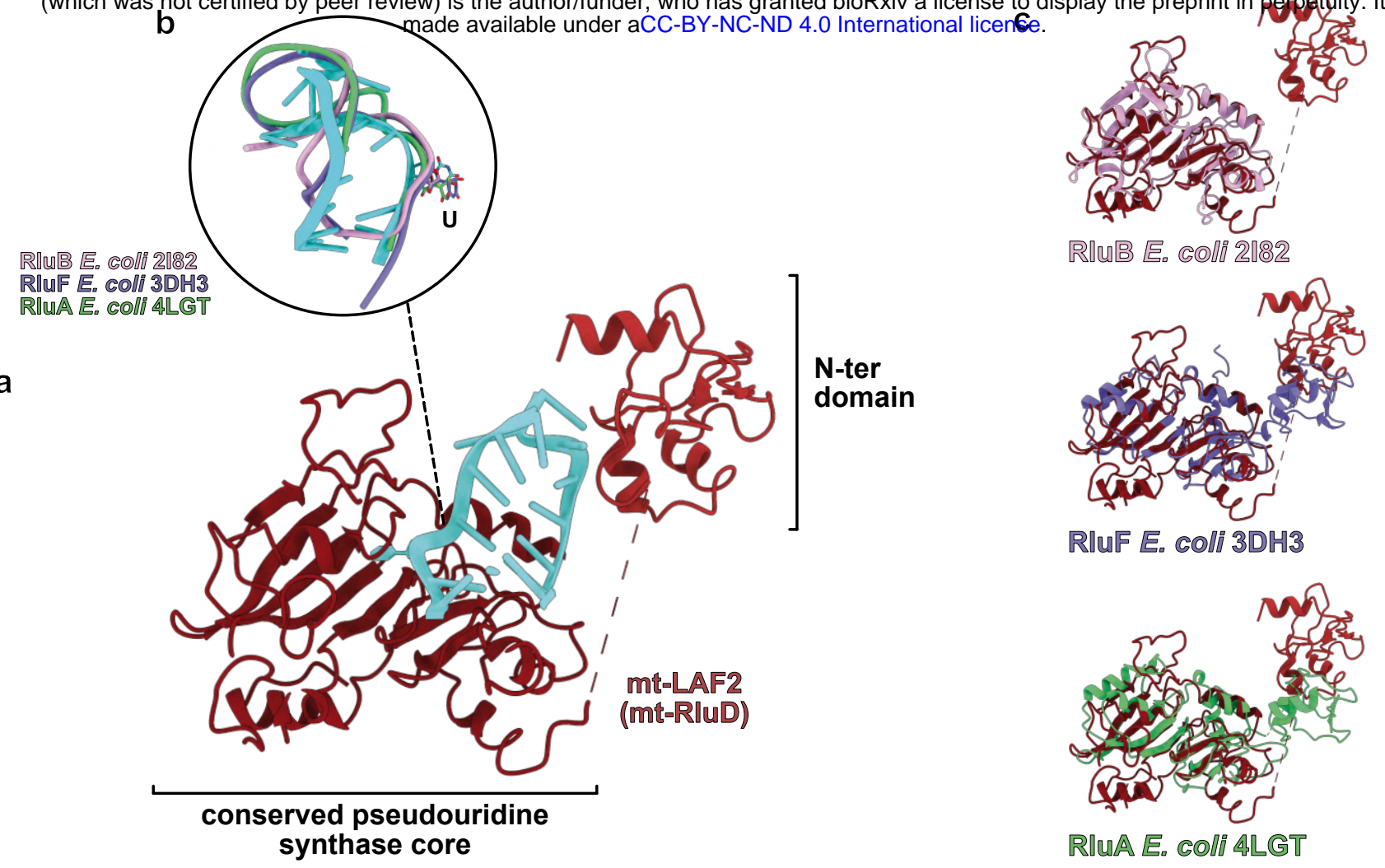

RInB E
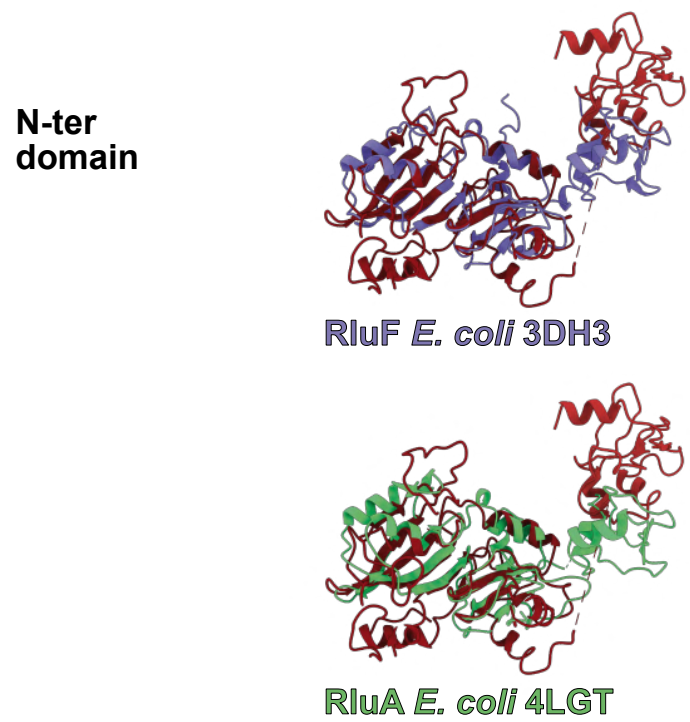

RIuF $E_{a}$ coll 3DH3

d
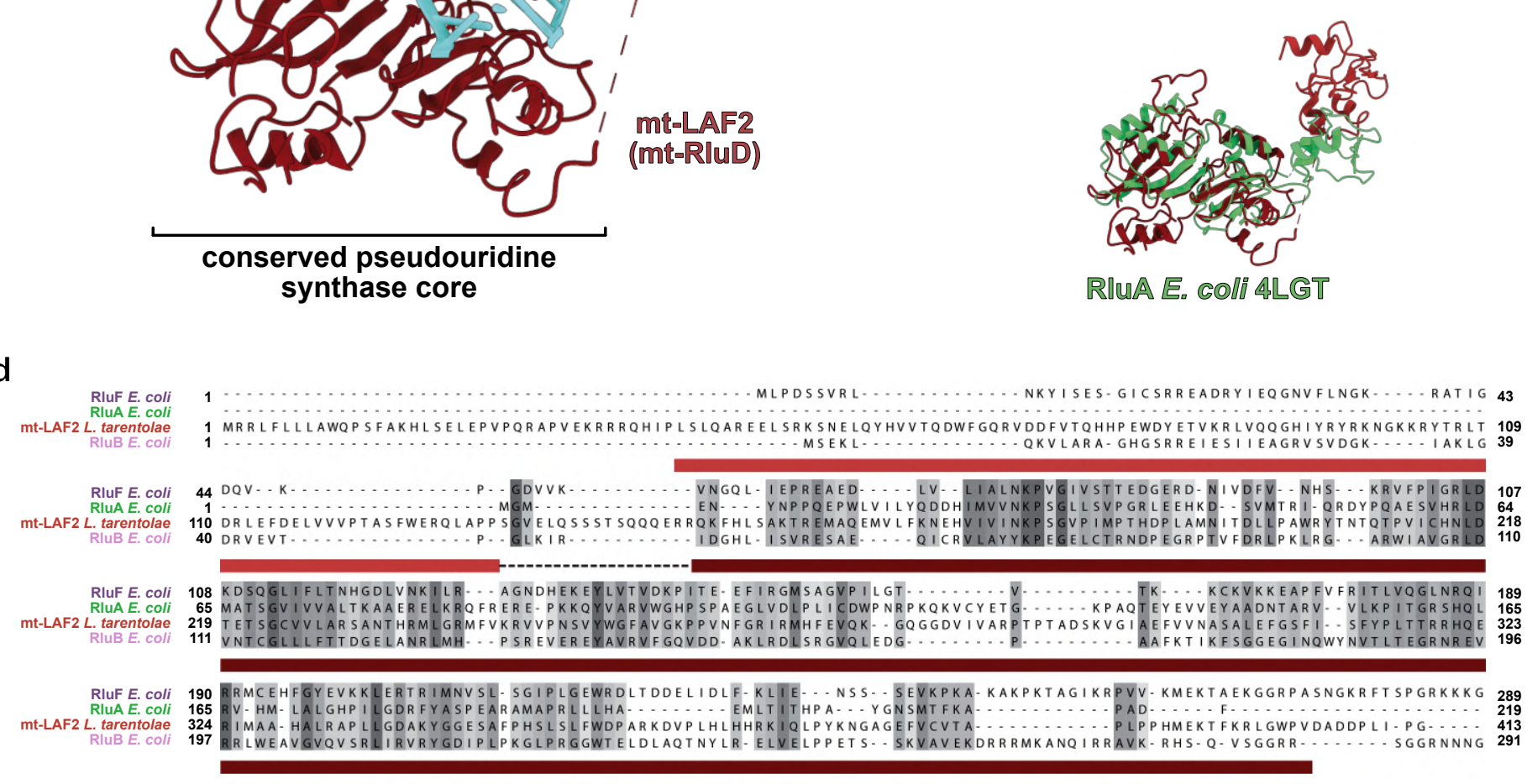

RIUA E. GOII ALGT

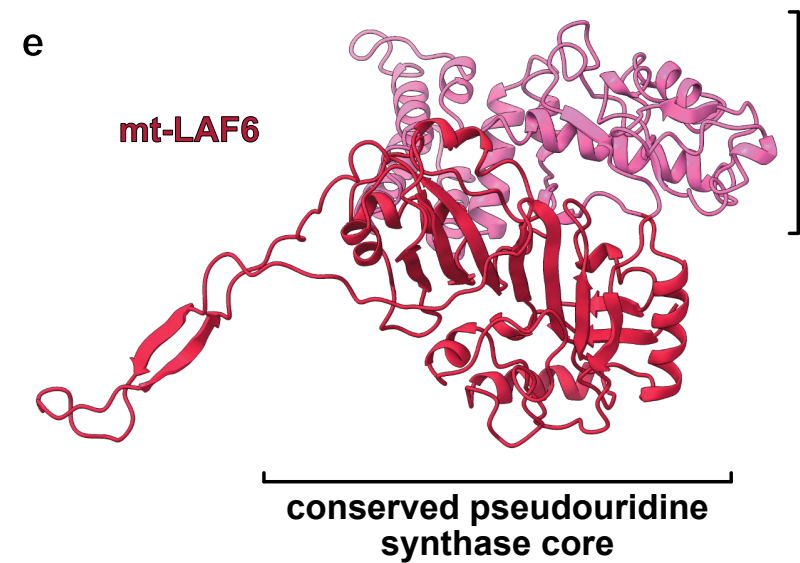

insertion domain

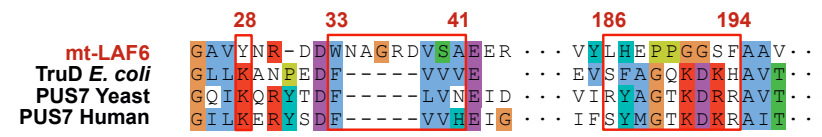
PUS7 Human

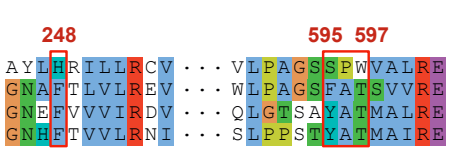

Extended Data Figure 8. Analysis of the pseudouridine synthases mt-LAF2 and mt-LAF6 Structural conservation and sequence comparison of the two pseudouridine synthases mt-LAF2 and mt-LAF6 are shown. In (a) the pseudouridine synthase mt-LAF6, homolog of the bacterial enzyme RluD ${ }^{19,20}$, is shown with its rRNA target (blue). The enzyme is particularly conserved with enzymes of the Rlu family, as highlighted by the superimpositions (c) and sequence alignments (d) of mt-LAF2 with $E$. coli Rlu enzymes. Its mode of action is also conserved, as shown in (b). In (e) the analysis of mt-LAF6 shows the presence of an insertion domain (pink) and sequence alignment with other pseudouridine synthases highlight that none of the catalytic sites of mt-LAF6 are conserved, mt-LAF6 is thus inactive. 
bioRxiv preprint doi: https://doi.org/10.1101/2020.05.02.073890; this version posted June 30, 2020. The copyright holder for this preprint (which was not certified by peer review) is the author/funder, who has granted bioRxiv a license to display the preprint in perpetuity. It is made available under aCC-BY-NC-ND 4.0 International license.

a

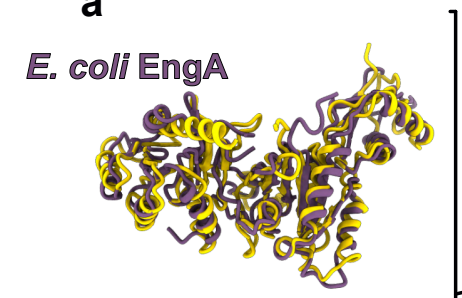

B. sußrilis Eng/A.

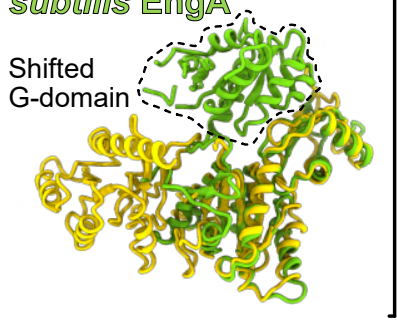

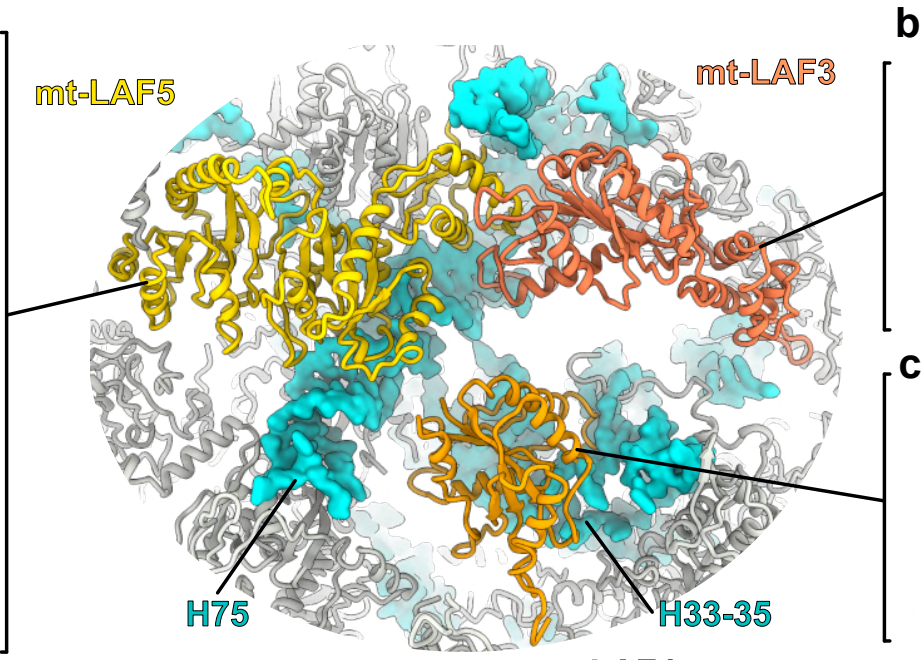

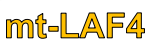

b

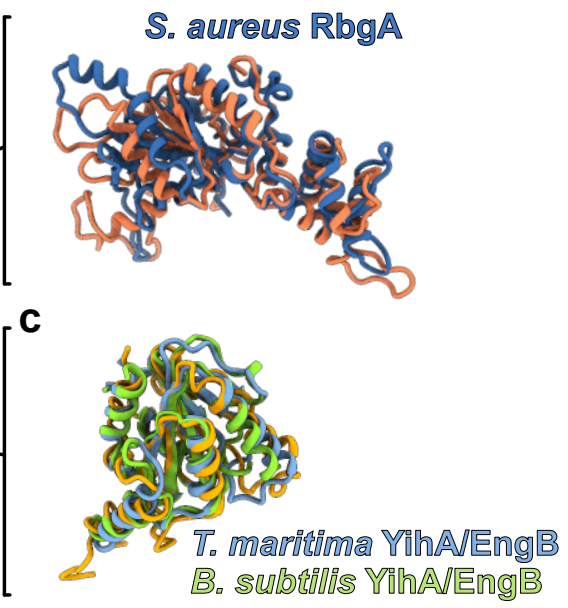

Extended Data Figure 9. Conservation of the three GTPases with their bacterial homologs

The three GTPases mt-LAF3, mt-LAF4 and mt-LAF5 are compared with their bacterial homologs. In (a) mt-LAF5 is compared with $B$. subtilis EngA crystal structure obtained with GDP, and $E$. coli EngA structure obtained by cryo-EM in complex with the LSU with excess of GMP-PNP, a non-hydrolysable analog of GTP (PDB: 3J8G and 5M7H). The $B$. subtilis one has its first G-domain shifted compared to E. coli EngA and mt-LAF5 which represent one of the alternative structural state of the GTPase. Thus, mt-LAF5 is in GTP state. (b) shows mt-LAF3 superimposed with S. aureus RbgA (PDB: 6G14). In (c) mt-LAF4 is superimposed with two crystal structures of its bacterial homolog YihA/ EngB (PDB: 3PQC and 1SVW). This protein was never observed in native assembly, but our reconstruction appear to be quasi-identical to the crystal structures previously obtained. In context of the LSU assembly intermediate, it interacts with $\mathrm{H} 54$ and appears here to block uL2m association. 
bioRxiv preprint doi: https://doi.org/10.1101/2020.05.02.073890; this version posted June 30, 2020. The copyright holder for this preprint a (which was not certified by peer review) is the author/funder, who has granted bioRxiv a license to display the preprint in perpetuity. It is

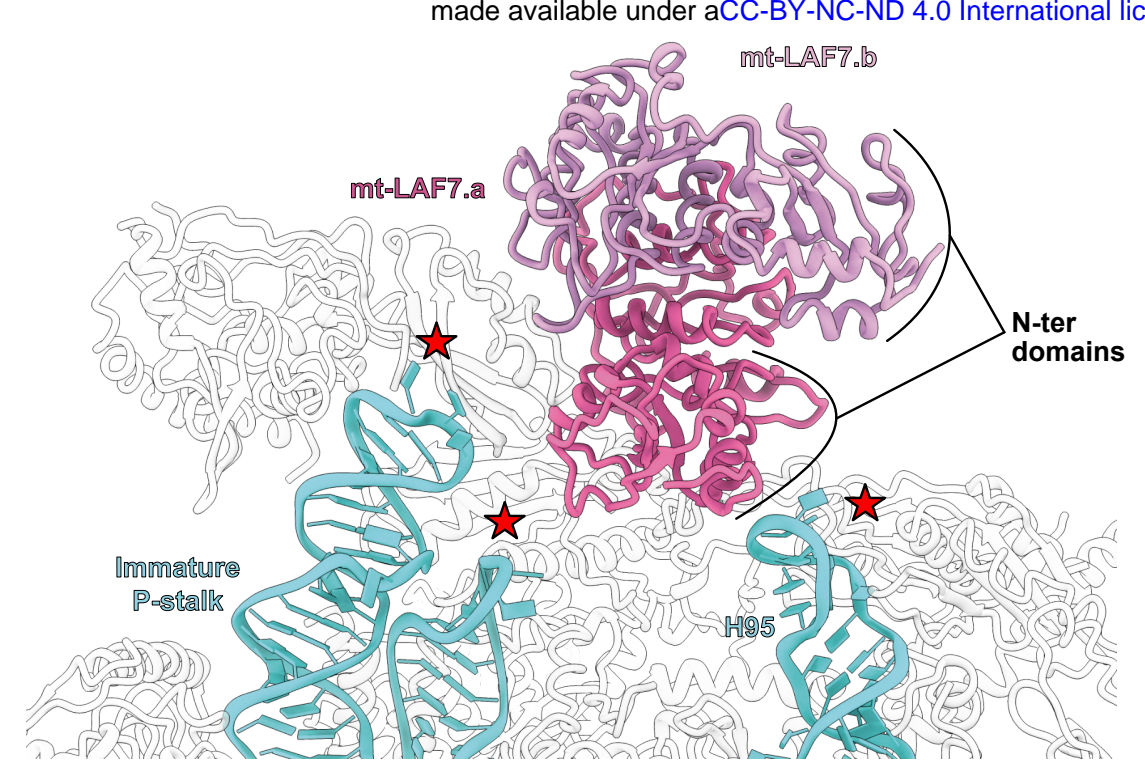

C

SAM Binding $\bullet$

S. cyaneuS VGNIGAIVRTSL.... ALLFGSEKGGPSD- LFEEASSASVSIPMMS... SLLNVSVSLGIAL

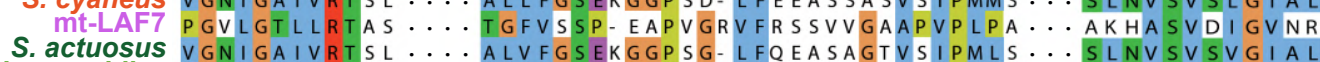
T. thermophilus PGNLGA ILRAAD .... AFLLGAEDKGLPE- AWKRRAQVRVRIPMRG ... SLNVAVTAALLL
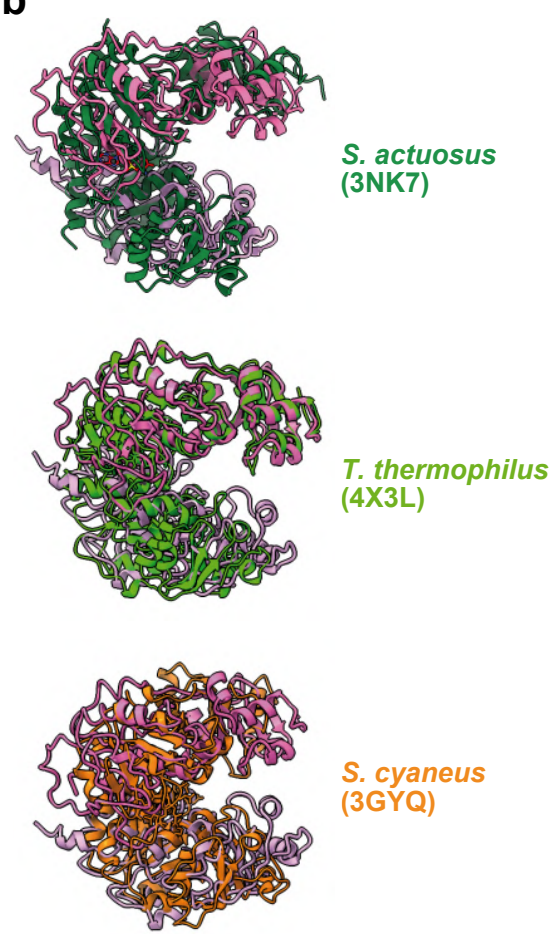

d

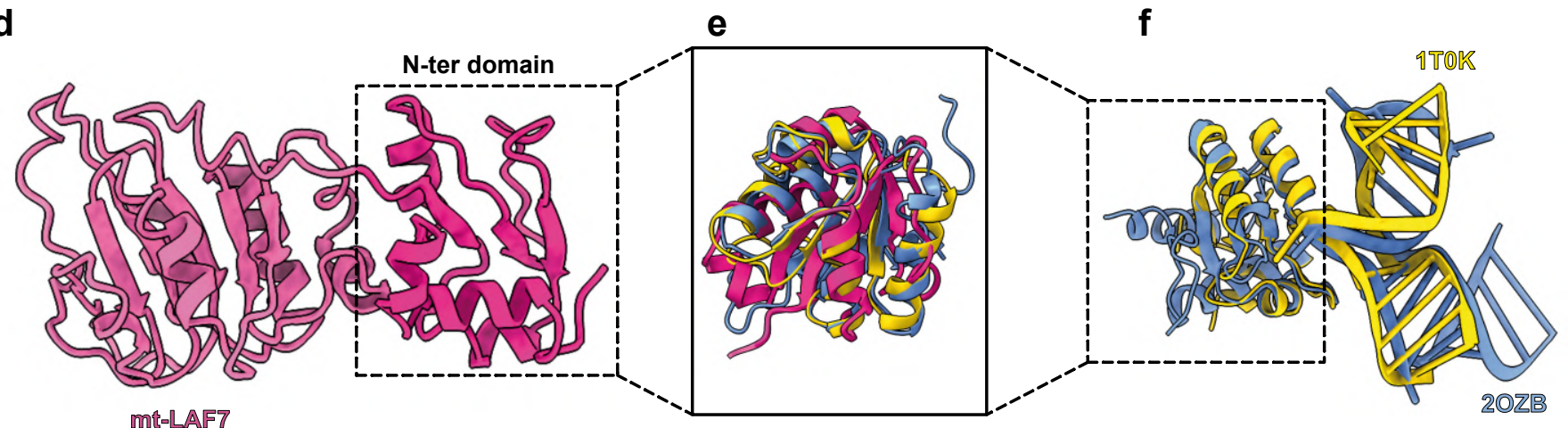

g

Loop 1

Loop 2

1TOK 20 FSASALAK.... IE. . . EGKLVIWINGDKGYNGLAEVGKKFEKDTGIKVTVEHPDKLEEKFPQVAATGDGPDI 85

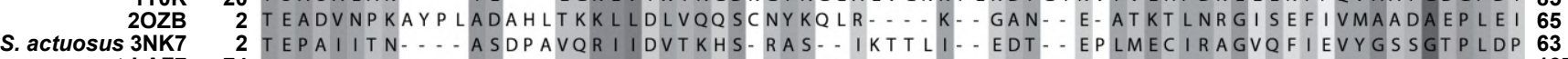

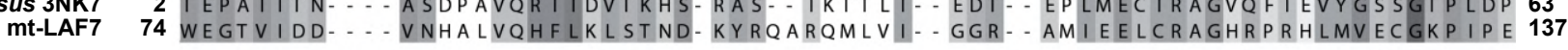

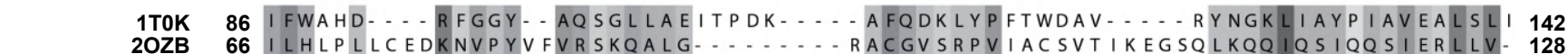

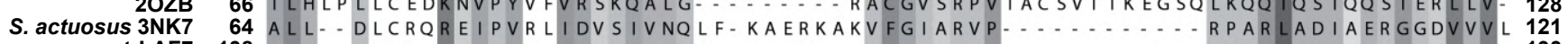

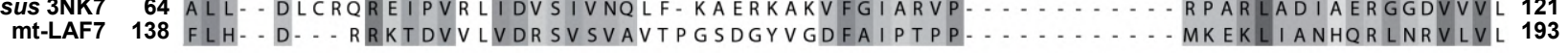

Loop 3

RNA binding loop

Extended Data Figure 10. Analysis of the RNA 2'O-methyltransferase mt-LAF7

The homodimeric mt-LAF7.a/mt-LAF7.b 2'O-methyltransferases are shown in the assembly intermediate context (a), with nearby possible rRNA targets - immature P-stalk and H95 - highlighted with a red star. Structural conservation is highlighted by structural superimpositions with several bacterial homologs, notably with S. actuosus NHR involved in P-stalk methylation ${ }^{41}$ (b), and crucial residues for the activity involved in S-adenosyl-I-methionine (SAM) binding are shown in (c). In (d-g) an analysis of the RNA binding N-terminal domain is shown. The N-terminal domain of mt-LAF7 (d) is superimposed (e) and the sequences are compared (g) with two eukaryotic proteins harbouring a similar dsRNA binding domain, which were structurally characterized in complex with their double stranded RNA target (f) as well as with S. actuosus NHR domain. 